\title{
Optimal transshipments and reassignments under periodic or cyclic holding cost accounting
}

\author{
N Çömez ${ }^{1}, \mathrm{M} C ̧ a k a n y ı l d ı r ı m^{2 *}$ and KE Stecke ${ }^{2}$ \\ ${ }^{1}$ Bilkent University, Ankara, Turkey; and ${ }^{2}$ University of Texas at Dallas, Richardson, TX, USA
}

In a centrally managed system, inventory at a retailer can be transshipped to a stocked-out retailer to meet demand. As the inventory at the former retailer may be demanded by future customers of that retailer and transshipment time/cost is non-negligible, it can be more profitable to not transship in some situations. When unsatisfied demand is backordered, reassignment of inventory to a previously backordered demand can perhaps become profitable as demand uncertainty resolves over time. Despite this intuition, we prove that no reassignments are necessary for cost optimality under periodic holding cost accounting in a two-retailer system. This remains valid for multi-retailer systems according to numerical analyses. When holding costs are accounted for only at the end of each replenishment cycle, reassignments are necessary for optimality but insignificant in reducing the total cost. In most instances tested, the decrease in total cost from reassignments is below $2 \%$ for end of cycle holding cost accounting. These results simplify transshipment policies and facilitate finding good policies in both implementation and future studies, as reassignments can be omitted from consideration in optimization models under periodic holding cost accounting and in approximation models under cyclical cost accounting.

Journal of the Operational Research Society (2013) 64, 1517-1539. doi:10.1057/jors.2012.135

Published online 21 November 2012

Keywords: inventory sharing; centrally managed inventory; stochastic inventory control

\section{Introduction}

Inventory sharing is an inventory pooling strategy where a retailer with available inventory shares units with a stocked-out retailer. Although inventories need not be physically pooled in an inventory sharing system, inventory costs can be decreased as in physical pooling. Besides retailers sharing inventory to satisfy end-customer demand, also distributors, warehouses, or manufacturers can share inventory to satisfy downstream demand. These contexts can be formulated as inventory sharing among retailers, which is the focus of this study wlog (without loss of generality).

A common method of inventory sharing is transshipping that happens in various forms in practice. Inventory can be transshipped in individual units upon a single demand realization or in small lots after a certain amount of unmet demand accumulation. Decisions can be centrally or independently managed by retailers. Most of these scenarios are investigated in the literature to a certain level. When future demand is uncertain at the time of

\footnotetext{
${ }^{*}$ Correspondence: $M$ Çakanyldirlm, School of Management, University of Texas at Dallas, PO. Box 830688, SM30, Richardson, TX, 75083, USA.

E-mail: metin@utdallas.edu
}

transshipment, retailers can sometimes prefer to share only a part (partial pooling) or none (no pooling) of their available inventory. Archibald et al (1997), Zhao et al (2008), and Çömez et al (2012a) obtain optimal partial pooling policies in centrally managed systems. Zhao et al (2006) and Çömez et al (2012b) develop policies for independent retailers.

In a centrally managed system, a transshipment request can be accepted or rejected by an inventory manager (IM). Expecting a high amount of future demand at a retailer, the IM can reject a transshipment request today to guard inventory at that retailer for later. When a transshipment request is rejected, the unsatisfied demand can be backordered and recorded in a customer database (including name, contact information, date, and backorder status). The retailer with inventory may discover a few days later that demand realization is less than expected and a high amount of leftover inventory is likely. Then the IM could revisit the denied transshipment request because transshipping at this time to meet the backordered demand in the database can decrease both inventory holding and backorder costs. Sharing a unit of inventory to satisfy a backordered demand (without a replenishment from a supplier) is called inventory reassignment. The term transshipment is reserved for sharing inventory to satisfy a new demand. Previous models do not distinguish between 
transshipments and reassignments as either reassignments are not relevant in lost sales models or backordered demands are assumed to be satisfied by only supplier replenishments. However, reassignments can be profitable and sometimes necessary for optimality.

Despite having sophisticated information and logistics infrastructure and because of lacking (near-)optimal policies, many IMs in practice opt for simple but suboptimal decision rules, that is, always accept or reject a (transshipment or reassignment) request. With a high number of backorders, backorder costs increase, as well as the psychological pressure from customer complaints. In order to maintain a reputable customer service, some IMs may be more likely to transship when there are more backorders. However, a transshipment policy that depends on the number of backorders is not very practical for an IM as it requires tracking the number of backorders at each retailer and a backordered customer database to contact each customer separately when a reassignment is initiated. On the other hand, it may be unfair to transship for a new customer while an existing customer is waiting for his demand to be satisfied. Such an unfair practice can damage the reputation of a retailer among customers. We aim to improve these practices by deriving optimal and fair policies, and pointing out when a cost-minimizing IM should consider reassignments and/or backorders. Since accepting a reassignment could be a profitable option, we explicitly consider both transshipments and reassignments to assess the possible benefit of reassignments under periodic or cyclic holding cost accounting. Our results can help researchers and managers assess the value of reassignments in different contexts.

We analytically study two centrally managed retailers selling the same product for the same price. Retailer inventories are replenished at the beginning of each replenishment cycle. A cycle is divided into shorter time intervals, called periods. For example, if a cycle is 22 eighthour working days in a month and a period is $4 \mathrm{~h}$, there are 44 periods in each month-long cycle. In each period, a retailer may satisfy the demand from a customer arriving to his individual location directly from stock, if available. If a retailer is out-of-stock and a customer demand occurs, then the stocked-out retailer makes a transshipment request. If the request is accepted, the unit is transshipped in a positive transshipment time at a non-zero transportation cost and the customer demand at the stocked-out retailer is satisfied. If not, the demand is backordered at the requesting retailer. For each period, a retailer incurs a backorder cost per demand backordered and a holding cost per unit of on-hand inventory. Holding cost accounting can be periodic (Çömez et al, 2012a) where the cost is assessed against the current on-hand inventory in each period or it can be cyclic (Archibald et al, 1997) when assessed against the leftover inventory at the end of a replenishment cycle.
This paper studies optimal transshipment and reassignment policies to answer three questions.

1. Do transshipment and/or reassignment decisions depend on the number of outstanding backorders?

2. Can reassignments, in addition to optimal transshipments, reduce the cost of the system?

3. How can policy computation and implementation be simplified by answering the questions above?

Under periodic holding cost accounting, the answers to the first two questions are both 'no'. In addition, we prove that once a retailer backorders a demand, then he should not transship for any of the newly arriving customers for the rest of the replenishment cycle. Without reassignments under periodic holding cost accounting, transshipments can be optimally determined with only the available inventory information in the current period. Thus, information on outstanding backorders is not needed for optimal inventory sharing. This significantly simplifies the state space of the system for computations. We show that the IM can compute a single critical number for each period and each retailer to manage the retailer system with optimal transshipments. Once these numbers are communicated to retailers as transshipment guidelines, the IM can delegate transshipment decisions to retailers. These results simplify implementation of the optimal transshipment policy.

We investigate how our results change with multiple $(>2)$ retailers and cyclic holding cost accounting. Our numerical analysis shows that reassignments remain unnecessary to minimize costs in the case of multiple retailers periodically accounting for holding costs. Under cyclic holding cost accounting, reassignments are surprisingly necessary for optimality, even for two retailers. The cost reduction that can be achieved with reassignments is not significant for reasonable system parameters. Therefore, a no-reassignment policy might be used as an effective heuristic for a retailer system with cyclic holding cost accounting and multiple retailers.

The literature review is in Section 2. In Section 3, the optimal transshipment policy is obtained and the unnecessity of reassignments for optimality is proved for periodic holding cost accounting. Holding cost accounting is cyclic in Section 4 and the resulting changes in transshipment policy are discussed. Section 5 has numerical analyses and Section 6 concludes the paper. All proofs are in the appendix.

\section{Literature review}

The literature mostly allows transshipments once at the end of a replenishment cycle, after all demand realizations. This makes replenishments as frequent as transshipments, 
which can be called cyclic transshipments. Replenishments in our model are much less frequent than transshipments, that is (cyclic), replenishments are at the beginning of each cycle, while (periodic) transshipments are considered in each period during a cycle. In Tagaras and Cohen (1992), Anupindi et al (2001), Rudi et al (2001), Hu et al (2007), and Zhao and Atkins (2009), at the beginning of a cycle, a replenishment from the manufacturer arrives. Demand realized during the cycle is satisfied from stock as long as there is enough stock. At the end of the cycle, if there is some demand that could not be satisfied from stock at some retailers and some unused inventory at other retailers, transshipments take place between retailers. As all transshipments are done after all demand is realized, there is no demand uncertainty in the cycle when transshipments take place. If there is some demand that is not satisfied after transshipments, it is backordered and filled by replenishments in the subsequent cycle. Reassignments (transshipments for backordered demand) or periodic transshipments are not considered in these studies.

In the studies described above, a complete pooling policy, where all on-hand inventory is available for transshipment, is used. In some problem settings, it can be more profitable to use a partial pooling policy, where only some part of on-hand inventory is used for transshipment, as in Granot and Sošić (2003) and Sošić (2006). These studies consider a single cycle, where transshipments are done after all demand is realized at all retailers. In these studies, there is no opportunity for reassignments as all transshipments are done at the end of the single cycle.

Some literature allows for transshipments after individual demand arrivals. Grahovac and Chakravarty (2001) and Kukreja et al (2001) formulate one-for-one replenishments so the frequency of replenishments and transshipments can be equal. If a transshipment is not available, an order to satisfy the demand is given to the distributor. Demand is backordered until this replenishment order arrives, that is, reassignment is not considered for any outstanding backorder.

Archibald et al (1997, 2010) allow multiple transshipments per cycle, for two-retailer and many-retailer systems, respectively. They model an emergency order instead of backordering when a transshipment is not available or profitable to use. Without backorder in these models, reassignment is not an option. In Çömez et al (2012a), all unsatisfied demand is backordered until the next replenishment.

Zhao et al (2005) model an $(S, K)$ policy for decentralized retailers, where $S$ is the order-up-to level and $K$ is the threshold inventory level above which a transshipment request is accepted. A retailer can reject a transshipment request initially but will ship a unit to the stockedout retailer when a replenishment order arrives. This is not inventory reassignment as a unit is shipped after a replenishment from a supplier.
With a long-run average cost objective, in addition to transshipments, Zhao et al (2008) consider replenishments, where the replenishment lead time is an exponential random variable. A decision epoch is either at a new demand or a replenishment arrival. Zhao et al show that the transshipment request from retailer $i$ to retailer $j$ is rejected if and only if $x_{i} \leqslant K_{i}\left(x_{j}-1\right)$, where $x_{i}$ and $x_{j}$ are inventory levels. The argument of the threshold function $K_{i}(\cdot)$ is the inventory (if negative, backorder) level at the stocked-out retailer $j$ except for the -1 term. So a transshipment decision depends on the backorder level at the stocked-out retailer. The model in Zhao et al considers transshipping to meet backorders when a replenishment arrives. So there is no consideration of reassignments. Our model differs from Zhao et al (2008). First, our discrete-time model allows reassignments in each period. Second, time between replenishments is constant in our model and random in Zhao et al. Thus, after considering reassignments, we can study monotonicity properties in the deterministic number of remaining periods until the next replenishment to prove unnecessity of reassignments in the optimal policy under periodic holding cost accounting.

\section{Optimal transshipments and reassignments under periodic holding cost accounting}

This section studies a model of two retailers, in which the cost of holding inventory is calculated periodically during a replenishment cycle. The optimal costs incurred during a cycle are computed with a dynamic program in Section 3.1. In Section 3.2, optimal transshipment and reassignment policies are obtained.

\subsection{Formulation}

A system of two retailers, whose replenishment, transshipment, and reassignment decisions are managed by a central IM, is studied. Retailer inventories are replenished at the beginning of each replenishment cycle. A discrete time model is developed by dividing each cycle into $N$ short decision periods. The periods are short enough so that at most one unit of demand is realized in each period, either at retailer 1 with probability $p_{1}$ or at retailer 2 with probability $p_{2}$ or at neither with probability $1-p_{1}-p_{2}$, where $p_{1}+p_{2} \leqslant 1$. Notation is summarized in Table 1. As $N$ increases by a factor and $p_{1}$ and $p_{2}$ decrease by the same factor, the demands converge to independent Poisson processes with means $N p_{1}$ and $N p_{2}$. For correlated demand models, see Çömez et al (2010). Discrete time models are common (Lee and Hersh 1993; Talluri and van Ryzin, 2004; Iravani et al, 2007) and facilitate the analysis of the IM's responses to an individual demand and a transshipment request. 
Table 1 Notation

\begin{tabular}{ccl}
\hline Parameters & $n$ & $\begin{array}{l}\text { Number of remaining periods } \\
\text { until the next replenishment }\end{array}$ \\
& $p_{i}$ & $\begin{array}{l}\text { Number of periods in a } \\
\text { replenishment cycle } \\
\text { Probability of a customer demand } \\
\text { at retailer } i \text { in a period } \\
\text { Transshipment time between the } \\
\text { retailers } \\
\text { Backorder cost per unit per period }\end{array}$ \\
& $h_{i}$ & $\begin{array}{l}\text { Holding cost per unit per period at } \\
\text { retailer } i\end{array}$ \\
& $h_{0}$ & $\begin{array}{l}\text { Holding cost per unit per period } \\
\text { during a transshipment } \\
\text { Transportation cost per unit } \\
\text { transshipped } \\
\text { Transshipment cost per unit } \\
\text { transshipped, } K^{\prime}:=K+T\left(b+h_{0}\right)\end{array}$ \\
$K^{\prime}$ & $\begin{array}{l}\text { Inventory level at retailer } i \text { at the } \\
\text { beginning of a period }\end{array}$ \\
& $x_{i}$ & $\begin{array}{l}\text { Minimum expected total cost for } \\
\text { the remaining } n \text { periods } \\
\text { Minimum expected total cost for } \\
\text { the remaining } n-1 \text { periods plus } \\
\text { the reassignment, holding, and } \\
\text { backorder costs in period } n\end{array}$ \\
$V_{n}\left(x_{1}, x_{2}\right.$ &
\end{tabular}

The number of decision periods remaining in a cycle until the next replenishment is $n, 0 \leqslant n \leqslant N$. In period $n$, a retailer with available on-hand inventory satisfies his customer's demand, if any. If the retailer has no inventory to satisfy his demand, he sends a transshipment request to the other retailer. The requesting retailer (he) requests a transshipment from the requested retailer (she). The requested retailer, depending on the IM's instruction, either accepts or rejects the request. If she accepts the request, the unit is transshipped and during the transshipment lead time $T$, a transportation cost $K$ is incurred. During the transshipment lead time, the unit is owned by the IM and the customer waits to receive the unit. Thus, a backorder cost $b T$ and a holding cost $h_{0} T$ are incurred by the IM, where $b$ is the backorder cost per unit per period and $h_{0}$ is the in-transit holding cost per unit per period. Because of positive transshipment costs and expectations on future demand at the requested retailer, the IM may advise the requested retailer to reject the request. Then the demand is backordered at the requesting retailer. For every backorder, the IM incurs a cost of $b$ per unit per period. Also, for available on-hand inventory at retailers 1 and 2, holding costs $h_{1}$ and $h_{2}$, respectively, are incurred per unit per period. So holding cost accounting is periodic in this section.

A rejected transshipment request becomes a backorder at a retailer and remains so until either a unit is reassigned from the other retailer or replenishments arrive at the end

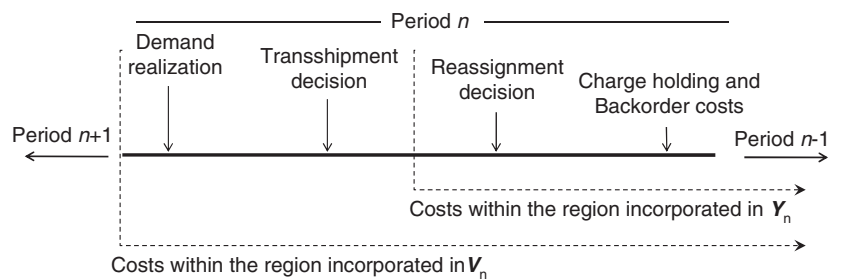

Figure 1 Scopes of functions $V_{n}$ and $Y_{n}$ in modelling expected costs.

of the cycle. If a unit is reassigned to the stocked-out retailer, it arrives at the stocked-out retailer in $T$ periods. Then the number of backorders at the stocked-out retailer and the inventory level at the other retailer both decrease by one. The reassignment cost of a unit is $K^{\prime}:=$ $T\left(b+h_{0}\right)+K$, which is the total cost of a unit shipped between retailers.

To obtain the optimal cost over a cycle, two value functions $V_{n}$ and $Y_{n}$ are defined in every period $n$. Let $V_{n}\left(x_{1}, x_{2}\right)$ be the minimum expected cost over the remaining $n$ periods with current inventory levels $x_{1}$ and $x_{2}$, at retailers 1 and 2 , respectively. $V_{n}$ is the sum of the cost of transshipment in period $n$, if any, and $Y_{n} . Y_{n}\left(x_{1}, x_{2}\right)$ is the minimum expected cost including the cost of reassignment in period $n$, plus the holding and backorder costs in period $n$, as well as all costs incurred in periods $n-1, n-2, \ldots, 1$. $V_{n}$ and $Y_{n}$ are value functions of a two-stage dynamic program in period $n$. The first stage deals with transshipment and the second stage deals with reassignment. Scopes of functions $V_{n}$ and $Y_{n}$ are illustrated in Figure 1.

In period $n$, if a retailer receives a demand and has onhand inventory, the demand is satisfied from the stock. Otherwise, if the other retailer has on-hand inventory, a transshipment decision is made, so that either a transshipment to satisfy the demand is sent or the demand is backordered. When both retailers are out-of-stock, any received demand is backordered. The $V_{n}$ in each of these situations are defined as follows. Inventory levels $x_{1}, x_{2}$ are integers.

$$
\begin{aligned}
V_{n}\left(x_{1}, x_{2}\right)= & p_{1} Y_{n}\left(x_{1}-1, x_{2}\right)+\left(1-p_{1}-p_{2}\right) Y_{n}\left(x_{1}, x_{2}\right) \\
& +p_{2} \min \left\{Y_{n}\left(x_{1}, x_{2}-1\right), K^{\prime}+Y_{n}\left(x_{1}-1, x_{2}\right)\right\}, \\
& x_{1} \geqslant 1, x_{2} \leqslant 0 .
\end{aligned}
$$

$$
\begin{aligned}
V_{n}\left(x_{1}, x_{2}\right)= & p_{2} Y_{n}\left(x_{1}, x_{2}-1\right)+\left(1-p_{1}-p_{2}\right) Y_{n}\left(x_{1}, x_{2}\right) \\
& +p_{1} \min \left\{Y_{n}\left(x_{1}-1, x_{2}\right), K^{\prime}+Y_{n}\left(x_{1}, x_{2}-1\right)\right\}, \\
& x_{1} \leqslant 0, x_{2} \geqslant 1 .
\end{aligned}
$$

$$
\begin{aligned}
V_{n}\left(x_{1}, x_{2}\right)= & p_{1} Y_{n}\left(x_{1}-1, x_{2}\right)+p_{2} Y_{n}\left(x_{1}, x_{2}-1\right) \\
& +\left(1-p_{1}-p_{2}\right) Y_{n}\left(x_{1}, x_{2}\right), \\
& x_{1}, x_{2} \leqslant 0 \text { or } x_{1}, x_{2} \geqslant 1 .
\end{aligned}
$$




$$
V_{0}\left(x_{1}, x_{2}\right)=0, \quad \text { for all } x_{1}, x_{2} \text {. }
$$

At the end of a replenishment cycle, the remaining inventories and backorders are carried to the next replenishment cycle to be used and satisfied, respectively.

In this paper, transshipments are considered only after stock-outs, following common practice and literature. Studies allowing transshipment before a stock-out such as Zhao et al (2006) and Grahovac and Chakravarty (2001) illustrated little need for such transshipments through numerical analyses, while Zhao et al (2008) restricted transshipments only to stock-out cases.

In period $n$, if there is a demand arrival, first the decision to satisfy this demand is made, either directly from stock or by using a transshipment. Then if there is an outstanding backorder, a reassignment decision, whether (or not) to transship one unit to satisfy one outstanding backorder, is made. $Y_{n}$ includes the (possible) cost of reassignment, if any, holding and backorder costs incurred in period $n$, and also the costs for the periods remaining until the next replenishment. Thus $Y_{n}$ depends on whether or not there is any backorder. For $n \geqslant 1$,

$$
\begin{gathered}
Y_{n}\left(x_{1}, x_{2}\right)=\min \left\{V_{n-1}\left(x_{1}, x_{2}\right)+b\left(-x_{2}\right)+h_{1} x_{1},\right. \\
K^{\prime}+V_{n-1}\left(x_{1}-1, x_{2}+1\right) \\
\left.+b\left(-x_{2}-1\right)+h_{1}\left(x_{1}-1\right)\right\}, \\
x_{1} \geqslant 1, x_{2} \leqslant-1 . \\
Y_{n}\left(x_{1}, x_{2}\right)=\min \left\{V_{n-1}\left(x_{1}, x_{2}\right)+b\left(-x_{1}\right)+h_{2} x_{2},\right. \\
K^{\prime}+V_{n-1}\left(x_{1}+1, x_{2}-1\right) \\
\left.+b\left(-x_{1}-1\right)+h_{2}\left(x_{2}-1\right)\right\}, \\
x_{1} \leqslant-1, x_{2} \geqslant 1 . \\
Y_{n}\left(x_{1}, x_{2}\right)=V_{n-1}\left(x_{1}, x_{2}\right)+h_{1} x_{1}+h_{2} x_{2}, \quad x_{1}, x_{2} \geqslant 0 . \\
Y_{n}\left(x_{1}, x_{2}\right)=V_{n-1}\left(x_{1}, x_{2}\right)+b\left(-x_{1}-x_{2}\right), \quad x_{1}, x_{2} \leqslant 0 .
\end{gathered}
$$

During a cycle, either retailer 1 or retailer 2 or neither may stock-out. Transshipment and reassignment decisions are needed when one of the retailers is stocked-out, while the other retailer has inventory. To study transshipment and reassignment decisions, wlog, the case when retailer 2 is stocked-out and retailer 1 has inventory is examined. Thus the transshipment and reassignment policies of retailer 1 are studied in the remainder of the paper. When main results are stated as theorems, they are generalized to both retailers.

\subsection{Optimal transshipments and reassignments}

To study transshipment and reassignment decisions, two cost differences are defined when retailer 2 is stocked-out. For $x_{2} \leqslant 0, \delta_{n}\left(x_{1}, x_{2}\right)=Y_{n}\left(x_{1}-1, x_{2}\right)-Y_{n}\left(x_{1}, x_{2}-1\right)$ for $n \geqslant 1$ and $\gamma_{n}\left(x_{1}, x_{2}\right)=V_{n}\left(x_{1}-1, x_{2}\right)-V_{n}\left(x_{1}, x_{2}-1\right)$ for $n \geqslant 0 . \delta_{n}$ and $\gamma_{n}$ can be computed recursively as shown in (8)-(13). These recursive equations are used subsequently to optimize transshipment and reassignment decisions. $\delta_{n}$ can be obtained from $\gamma_{n-1}$ for $n \geqslant 1$.

$$
\begin{aligned}
\delta_{n}\left(x_{1}, x_{2}\right)= & \gamma_{n-1}\left(x_{1}, x_{2}\right)-b-h_{1} \\
& +\min \left\{b+h_{1}, K^{\prime}+\gamma_{n-1}\left(x_{1}-1, x_{2}+1\right)\right\} \\
& -\min \left\{b+h_{1}, K^{\prime}+\gamma_{n-1}\left(x_{1}, x_{2}\right)\right\}, \\
& x_{1} \geqslant 2, x_{2} \leqslant-1 . \\
\delta_{n}\left(x_{1}, x_{2}\right)= & \gamma_{n-1}\left(x_{1}, x_{2}\right)-\min \left\{b+h_{1}, K^{\prime}+\gamma_{n-1}\left(x_{1}, x_{2}\right)\right\}, \\
& x_{1} \geqslant 1, x_{2}=0 \text { or } x_{1}=1, x_{2} \leqslant-1 . \\
& \delta_{n}\left(x_{1}, x_{2}\right)=\gamma_{n-1}\left(x_{1}, x_{2}\right), \quad x_{1}, x_{2} \leqslant 0 .
\end{aligned}
$$

Equations (8) and (10) are obtained from, respectively, (5) and (7). Equation (9) is obtained from (5), (6), and (7). For $n=1$, we have $\gamma_{n-1}=\gamma_{0}$ and $\gamma_{0}\left(x_{1}, x_{2}\right)=0$ for all $x_{1}, x_{2}$ from (4). For $n \geqslant 2, \gamma_{n}$ is obtained from $\delta_{n}$.

$$
\begin{aligned}
\gamma_{n}\left(x_{1}, x_{2}\right)= & p_{1} \delta_{n}\left(x_{1}-1, x_{2}\right)+\left(1-p_{1}-p_{2}\right) \delta_{n}\left(x_{1}, x_{2}\right) \\
& +p_{2}\left[\delta_{n}\left(x_{1}, x_{2}-1\right)+\min \left\{0, K^{\prime}+\delta_{n}\left(x_{1}-1, x_{2}\right)\right\}\right. \\
& \left.-\min \left\{0, K^{\prime}+\delta_{n}\left(x_{1}, x_{2}-1\right)\right\}\right], \\
& x_{1} \geqslant 2, x_{2} \leqslant 0 .
\end{aligned}
$$

$$
\begin{aligned}
\gamma_{n}\left(x_{1}, x_{2}\right)= & p_{1} \delta_{n}\left(0, x_{2}\right)+\left(1-p_{1}-p_{2}\right) \delta_{n}\left(1, x_{2}\right) \\
& +p_{2}\left[\delta_{n}\left(1, x_{2}-1\right)-\min \left\{0, K^{\prime}+\delta_{n}\left(1, x_{2}-1\right)\right\}\right], \\
& x_{1}=1, x_{2} \leqslant 0 . \\
\gamma_{n}\left(x_{1}, x_{2}\right)= & p_{1} \delta_{n}\left(x_{1}-1, x_{2}\right)+p_{2} \delta_{n}\left(x_{1}, x_{2}-1\right) \\
& +\left(1-p_{1}-p_{2}\right) \delta_{n}\left(x_{1}, x_{2}\right), \quad x_{1}, x_{2} \leqslant 0 .
\end{aligned}
$$

Equations (11) and (13) are obtained from, respectively, (1) and (3). Equation (12) is obtained from (1) and (3).

Transshipment and reassignment decisions can be expressed in terms of $\delta_{n}$ and $\gamma_{n}$. From (1), when retailers have $x_{1} \geqslant 1$ and $x_{2} \leqslant 0$ in period $n$, a unit is transshipped from retailer 1 to retailer 2 to satisfy a new demand at retailer 2 if and only if

$$
\delta_{n}\left(x_{1}, x_{2}\right) \leqslant-K^{\prime} .
$$

From (5), when retailers have $x_{1} \geqslant 1$ and $x_{2} \leqslant-1$ in period $n$, a unit is reassigned from retailer 1 to retailer 2 if and only if

$$
\gamma_{n-1}\left(x_{1}, x_{2}+1\right) \leqslant b+h_{1}-K^{\prime} .
$$

The similarity of the transshipment and reassignment conditions in (14)-(15) hint that transshipment and reassignment policies may be similar. Before studying this 
similarity, some monotonicity results are provided in inventory and over time by Lemma 1 .

Lemma 1 For $n \geqslant 1, x_{1} \geqslant 1$, and $x_{2} \leqslant 0$,

(i) $\delta_{n}\left(x_{1}, x_{2}\right)$ is non-increasing in $x_{1}: \delta_{n}\left(x_{1}, x_{2}\right) \leqslant \delta_{n}\left(x_{1}-1\right.$, $\left.x_{2}\right)$,

(ii) $\gamma_{n}\left(x_{1}, x_{2}\right)$ is non-increasing in $x_{1}: \gamma_{n}\left(x_{1}, x_{2}\right) \leqslant$ $\gamma_{n}\left(x_{1}-1, x_{2}\right)$

(iii) $\delta_{n}\left(x_{1}, x_{2}\right)$ is non-increasing in $n: \delta_{n+1}\left(x_{1}, x_{2}\right) \leqslant$ $\delta_{n}\left(x_{1}, x_{2}\right)$, and

(iv) $\gamma_{n}\left(x_{1}, x_{2}\right)$ is non-increasing in $n$ : $\gamma_{n+1}\left(x_{1}, x_{2}\right) \leqslant$ $\gamma_{n}\left(x_{1}, x_{2}\right)$

A transshipment request made by retailer 2 to retailer 1 is accepted in period $n$ with inventory levels $\left(x_{1}, x_{2}\right)$, if condition (14) holds. The right-hand side of (14) is constant. The left-hand side is non-increasing in $x_{1}$ by Lemma 1(i). Given two inventory levels $x_{1}$ and $x_{1}{ }^{\prime}, x_{1}{ }^{\prime} \geqslant x_{1}$, if the transshipment request is accepted with inventory level $x_{1}$, it must also be accepted with inventory $x_{1}{ }^{\prime}$. If the transshipment request is rejected with inventory $x_{1}$, it must also be rejected with inventory $x_{1}^{\prime \prime}$, for $x_{1}{ }^{\prime \prime} \leqslant x_{1}$. Thus Lemma 1(i) leads to the existence of an optimal transshipment policy based on holdback (inventory threshold) levels.

Similarly, a reassignment is made from retailer 1 to retailer 2 in period $n$ with inventory levels $\left(x_{1}, x_{2}\right)$ if condition (15) is satisfied, in which the left-hand side is shown to be non-increasing in $x_{1}$ by Lemma 1(ii) and the right-hand side is constant. Monotonicity of $\gamma_{n}$ in $x_{1}$ assures that reassignments from retailer 1 to retailer 2 can also be based on holdback levels. The optimal holdback levels for transshipments do not have to be the same as those for reassignments.

Lemma 1 is sufficient to define holdback level-based transshipment and reassignment policies. However, an aim of this study is to examine the dependence of transshipment and reassignment decisions on outstanding backorders, which is not addressed by Lemma 1. Next, benefiting from Lemma 1, Lemma 2 states that optimal transshipment and reassignment decisions are independent of outstanding backorders.

Lemma 2 For each $n$ and $\left(x_{1}, x_{2}\right)$ where $x_{1} \geqslant 1$ and $x_{2} \leqslant 0$, the following results hold.

(A) One and only one of the following two statements holds.

$$
\begin{aligned}
& \text { (i) } \delta_{n}\left(x_{1}, x_{2}-1\right)=\delta_{n}\left(x_{1}, x_{2}\right)>-K^{\prime} \\
& \text { or } \quad \text { (ii) } \delta_{n}\left(x_{1}, x_{2}-1\right) \leqslant \delta_{n}\left(x_{1}, x_{2}\right) \leqslant-K^{\prime} .
\end{aligned}
$$

(B) One and only one of the following two statements holds.

$$
\begin{aligned}
& \text { (iii) } \gamma_{n}\left(x_{1}, x_{2}-1\right)=\gamma_{n}\left(x_{1}, x_{2}\right)>b+h_{1}-K^{\prime} \\
& \text { or } \quad \text { (iv) } \gamma_{n}\left(x_{1}, x_{2}-1\right) \leqslant \gamma_{n}\left(x_{1}, x_{2}\right) \leqslant b+h_{1}-K^{\prime} .
\end{aligned}
$$

Lemma 2 shows that transshipment and reassignment decisions are insensitive to the number of backorders. To see this, consider two inventory levels at retailer $2, x_{2}{ }^{\prime}$ and $x_{2}{ }^{\prime \prime}$, where $x_{2}{ }^{\prime}<x_{2}{ }^{\prime \prime}<0$. So $-x_{2}^{\prime}$ and $-x_{2}{ }^{\prime \prime}$ denote the number of backorders. Suppose that it is optimal to transship a unit from retailer 1 to retailer 2 when there are $-x^{\prime \prime}{ }_{2}$ backorders at retailer 2 . Then from (14), $\delta_{n}\left(x_{1}\right.$, $\left.x^{\prime \prime}{ }_{2}\right) \leqslant-K^{\prime}$ holds. By Lemma 2(A(ii)), $\delta_{n}\left(x_{1}, x_{2}\right) \leqslant \ldots \leqslant$ $\delta_{n}\left(x_{1}, x^{\prime \prime}{ }_{2}\right) \leqslant-K^{\prime}$. Thus when the inventory level is $x_{2}{ }^{\prime},(14)$ still holds, that is, it is also optimal to transship when the backorder is $-x_{2}^{\prime}$ On the other hand, suppose that it is optimal to not transship a unit from retailer 1 to retailer 2 when retailer 2 has $-x_{2}^{\prime \prime}$ units of backorders, that is, $\delta_{n}\left(x_{1}, x_{2}^{\prime \prime}\right)>-K^{\prime}$ by (14). Combining this with Lemma $2(\mathrm{~A}(\mathrm{i}))$, it follows that $\delta_{n}\left(x_{1}, x_{2}^{\prime}\right)=\ldots=\delta_{n}\left(x_{1}, x^{\prime \prime}{ }_{2}\right)>$ $-K^{\prime}$. Thus, when the number of backorders is $-x_{2}^{\prime}$, it is not optimal to transship by (14). In conclusion, the optimal decision to transship from retailer 1 to retailer 2 can be made irrespective of the number of backorders at retailer 2 . By using Lemma 2(B), a similar conclusion can be made regarding a reassignment decision. Optimal reassignment decisions are independent of the number of backorders.

Recall that Lemma 1(i) and 1(ii) lead to the existence of optimal transshipment and reassignment policies, each based on holdback levels. Lemma 1(iii) says that for a fixed number of backorders at retailer 2 and the fixed on-hand inventory at retailer $1 \quad\left(x_{1} \geqslant 1\right.$ and $\left.x_{2} \leqslant 0\right), \delta_{n}\left(x_{1}, x_{2}\right)$ decreases (not strictly) in $n$, that is, $\delta_{n}\left(x_{1}, x_{2}\right)$ increases (not strictly) in calendar time. Then it is better to transship earlier in a cycle (when $n$ is larger) than to transship closer to the end of the cycle. Similarly, Lemma 1(iv) leads to the monotonicity of reassignment holdback levels in time. Combining the existence and monotonicity of transshipment and reassignment holdback levels with Lemma 2, optimal transshipment and reassignment policies are formally defined in Theorem 1.

\section{Theorem 1}

1. For each period $n$, there exists a holdback level $\widetilde{x}_{i}^{n}$ for retailer $i$ such that it is optimal to reject (respectively, accept) a transshipment request when $x_{i} \leqslant \widetilde{x}_{i}^{n}$ (respectively, $x_{i}>\widetilde{x}_{i}^{n}$ ).

2. The transshipment holdback level is non-increasing in the remaining number of periods: $\widetilde{x}_{i}^{n+1} \leqslant \widetilde{x}_{i}^{n}$

3. For each period $n$, there exists a reassignment holdback level $\hat{x}_{i}^{n}$ for retailer $i$ such that it is optimal to reject (respectively, accept) a reassignment request when $x_{i} \leqslant \hat{x}_{i}^{n}$ (respectively, $x_{i}>\widehat{x}_{i}^{n}$ ).

4. The reassignment holdback level is non-increasing in the remaining number of periods: $\widehat{x}_{i}^{n+1} \leqslant \widehat{x}_{i}^{n}$.

Next we show that the optimal responses to both (transshipment and reassignment) requests are the same. If a transshipment request for a new demand is accepted 
(rejected) with inventory $\left(x_{1}, x_{2}\right)$ in period $n$, a reassignment request is also accepted (rejected) with inventory $\left(x_{1}, x_{2}\right)$ in period $n$.

Lemma 3 In period $n$, it is optimal to accept a transshipment request if and only if it is optimal to accept a reassignment request: $\delta_{n}\left(x_{1}, x_{2}\right) \leqslant-K^{\prime}$ if and only if $\gamma_{n-1}\left(x_{1}, x_{2}+1\right) \leqslant b+h_{1}-K^{\prime}$ for $x_{1} \geqslant 1$ and $x_{2} \leqslant 0$.

From Lemma 3, transshipment and reassignment decisions are governed by the same holdback levels $\tilde{x}_{i}^{n}=$ $\hat{x}_{i}^{n}$, which are non-decreasing in calendar time. Note that if the inventory level is less than the holdback level in a period, it remains less until the next replenishment. Let $\mathcal{T}_{i}$ be the number of remaining periods in a cycle when the inventory at retailer $i$ drops to her holdback level for the first time in the cycle. Then retailer $i$ accepts (both transshipment and reassignment) requests in periods $n \in\left\{\mathcal{T}_{i}+1, \ldots, N\right\}$ and rejects in periods $n \in\left\{1, \ldots, \mathcal{T}_{i}\right\} . \mathcal{T}_{i}$ is a stopping time for retailer $i$ and it depends on random demand realizations during the cycle.

A demand in backorder in period $n$ can be traced back in time to the period $n^{\prime}$ that it was first backordered because either there was no inventory at the retailers when it arrived or a transshipment request to satisfy this demand was rejected. Although period $n^{\prime}$ is before period $n$ in calendar time, we have $n^{\prime}>n$ as a consequence of numbering periods backward in time. If the retailers did not have any inventory in period $n^{\prime}$, they would not have any in period $n$, so the IM cannot reassign inventory to meet backordered demand. Otherwise, there was on-hand inventory at the other retailer $i$ when this demand arrived in period $n^{\prime}$. Since the transshipment request is rejected in period $n^{\prime}$, we must have $\mathcal{T}_{i}>n^{\prime}$. Combining this with $n^{\prime}>n$, we obtain $\mathcal{T}_{i}>n$. So retailer $i$ continues to reject not only transshipment requests but also reassignment requests by Lemma 3. In summary, the presence of backorders at one retailer is an indication that the other retailer is optimally rejecting requests. In other words, it is optimal to reject all of the reassignment requests.

This result also rules out an unfair but possible implementation, where a new customer's demand is satisfied through a transshipment before the demand of a customer waiting for a reassignment. Presence of a waiting (backordered) customer at a retailer in our optimal policy ensures that the other retailer has been and will be rejecting requests. Hence, demands are satisfied fairly in the order of their arrival in our optimal policy. These interesting results and characteristics of the optimal transshipment and reassignment policies are specified in Theorem 2 .

\section{Theorem 2}

(i) The optimal transshipment policy is such that in each period $n$, retailer $i$ transships to the other stocked-out retailer if and only if $x_{i}>\tilde{x}_{i}^{n}$. Also, the holdback level is non-increasing in the remaining number of periods: $\tilde{x}_{i}^{n+1} \leqslant \tilde{x}_{i}^{n}$

(ii) The optimal reassignment policy is that it is never optimal to reassign.

In summary, Theorem 2 shows that transshipments for newly arrived demand are done according to optimal holdback levels, which depend only on the parameters in Table 1 but not on backorders. If a transshipment for a new demand is not optimal and the demand is backordered, then it is never optimal to reassign for this backordered demand. It is optimal to backorder the demand until the next replenishment.

The transshipment problem formulation can be simplified by benefiting from the independence of transshipment decisions from the amount of backorders. Since it is optimal to not reassign, the reassignment decision can be removed from the model. Accordingly, (5)-(7) collapse into a single cost equality: $Y_{n}\left(x_{1}, x_{2}\right)=V_{n-1}\left(x_{1}, x_{2}\right)+h_{1} x_{1}^{+}+$ $h_{2} x_{2}^{+}+b\left(x_{1}^{-}+x_{2}^{-}\right)$, where $x^{+}=\max \{0, x\}$ and $x^{-}=$ $\max \{0,-x\}$. This cost equality can be inserted in (1)-(3) to eliminate $Y_{n}$ from cost computations.

According to Theorem 2(ii), backorders do not decrease and can only increase over time. Since backorders remain backorders, the entire backorder cost for a unit, $n b$, can be charged when it is backordered in period $n$. This leads to an alternative backorder cost accounting such that the expected cost for the remaining $n$ periods can be denoted by $V_{n}^{\prime}\left(x_{1}, x_{2}\right)=V_{n}\left(x_{1}, x_{2}\right)-n b\left(x_{1}^{-}+x_{2}^{-}\right)$, for all $x_{1}$ and $x_{2}$. Then, $V_{n}^{\prime}\left(x_{1}, x_{2}\right)$ does not include any backorder cost for already backordered demands, that is, $V_{\mathrm{n}}^{\prime}\left(x_{1}, x_{2}\right)=V_{n}^{\prime}\left(x_{1}\right.$, $\left.x_{2}-1\right)$ for $x_{2} \leqslant 0$. The marginal benefit of a unit inventory at retailer 1 can written as a function of only $x_{1}$, that is, $\delta_{n}^{\prime}\left(x_{1}\right)=V_{n}^{\prime}\left(x_{1}-1, x_{2}\right)-V_{n}^{\prime}\left(x_{1}, x_{2}\right)$. Accordingly, a transshipment request is accepted in period $n$ if and only if

$$
\delta_{n-1}^{\prime}\left(x_{1}\right) \leqslant n b+h-K^{\prime} .
$$

Computation of $V_{n}^{\prime}$ is easier than $V_{n}$, because recursive equations are shorter than those in (1)-(7) and $Y_{n}$ is eliminated. By using $\delta_{n-1}^{\prime}\left(x_{1}\right)$ computed from $V_{n}^{\prime}$, in which backorder costs are charged item by item until the next replenishment, and the transshipment acceptance condition $\delta^{\prime}{ }_{n-1}\left(x_{1}\right) \leqslant n b+h-K^{\prime}$, the transshipment policy can be obtained more easily.

\section{Optimal transshipments and reassignments under cyclic holding cost accounting}

In Section 3, it is proved that a reassignment is never used with optimal transshipments under PHA (periodic holding cost accounting). On the other hand, CHA (cyclic holding cost accounting) simplifies cost computation within the cycle. A CHA scheme may be suitable when the holding 
cost for inventory held during the cycle is not significant. However, when the holding cost accounting used by the IM changes, the structure of the optimal transshipment and reassignment policies may be affected. To investigate this, transshipment and reassignment policies are next studied under CHA.

The cost functions $V_{n}$ and $Y_{n}$ are redefined under CHA: (1), (2), and (3) remain the same. Only (4) changes as follows.

$$
V_{0}\left(x_{1}, x_{2}\right)=h_{1} x_{1}^{+}+h_{2} x_{2}^{+}, \text {for all } x_{1}, x_{2} .
$$

No holding cost is charged in a period under CHA, so $Y_{n}$ for $n \geqslant 1$ is redefined as follows.

$$
\begin{aligned}
& Y_{n}\left(x_{1}, x_{2}\right)=\min \left\{V_{n-1}\left(x_{1}, x_{2}\right)+b\left(-x_{2}\right), K^{\prime}\right. \\
& \left.+V_{n-1}\left(x_{1}-1, x_{2}+1\right)+b\left(-x_{2}-1\right)\right\}, \\
& x_{1} \geqslant 1, x_{2} \leqslant-1 \text {. } \\
& Y_{n}\left(x_{1}, x_{2}\right)=\min \left\{V_{n-1}\left(x_{1}, x_{2}\right)+b\left(-x_{1}\right), K^{\prime}\right. \\
& \left.+V_{n-1}\left(x_{1}+1, x_{2}-1\right)+b\left(-x_{1}-1\right)\right\} \\
& x_{1} \leqslant-1, x_{2} \geqslant 1 \text {. } \\
& Y_{n}\left(x_{1}, x_{2}\right)=V_{n-1}\left(x_{1}, x_{2}\right), \quad x_{1}, x_{2} \geqslant 0 . \\
& Y_{n}\left(x_{1}, x_{2}\right)=V_{n-1}\left(x_{1}, x_{2}\right)+b\left(-x_{1}-x_{2}\right), \quad x_{1}, x_{2} \leqslant 0 \text {. }
\end{aligned}
$$

Wlog, transshipment and reassignment decisions are studied for retailer 1 when retailer 2 is stocked-out. Then difference functions $\delta_{n}\left(x_{1}, x_{2}\right)=Y_{n}\left(x_{1}-1, x_{2}\right)-Y_{n}\left(x_{1}, x_{2}-1\right)$ and $\gamma_{n}\left(x_{1}, x_{2}\right)=V_{n}\left(x_{1}-1, x_{2}\right)-V_{n}\left(x_{1}, x_{2}-1\right)$ are needed for $x_{2} \leqslant 0$. For $n \geqslant 1$,

$$
\begin{gathered}
\delta_{n}\left(x_{1}, x_{2}\right)=\gamma_{n-1}\left(x_{1}, x_{2}\right)-b \\
+\min \left\{b, K^{\prime}+\gamma_{n-1}\left(x_{1}-1, x_{2}+1\right)\right\} \\
-\min \left\{b, K^{\prime}+\gamma_{n-1}\left(x_{1}, x_{2}\right)\right\}, \\
x_{1} \geqslant 2, x_{2} \leqslant-1 . \\
\delta_{n}\left(x_{1}, x_{2}\right)=\gamma_{n-1}\left(x_{1}, x_{2}\right)-\min \left\{b, K^{\prime}+\gamma_{n-1}\left(x_{1}, x_{2}\right)\right\}, \\
x_{1} \geqslant 1, x_{2}=0 \quad \text { or } \quad x_{1}=1, x_{2} \leqslant-1 . \\
\delta_{n}\left(x_{1}, x_{2}\right)=\gamma_{n-1}\left(x_{1}, x_{2}\right), \quad x_{1}, x_{2} \leqslant 0 .
\end{gathered}
$$

While defining $\gamma_{n}$, (11), (12), and (13) remain the same. For $n=0$,

$$
\gamma_{0}\left(x_{1}, x_{2}\right)=-h_{1} 1_{x_{1} \geqslant 1}, \quad x_{2} \leqslant 0 .
$$

The indicator variable $1_{x_{1} \geqslant 1}$ is equal to 1 , if $x_{1} \geqslant 1$ and 0 , otherwise.

Transshipment and reassignment decisions can be expressed in terms of $\delta_{n}$ and $\gamma_{n}$. When retailers have inventory $\left(x_{1}, x_{2}\right)$ in period $n$, a unit is transshipped from retailer 1 to retailer 2 to satisfy a new demand at retailer 2 if and only if $\delta_{n}\left(x_{1}, x_{2}\right) \leqslant-K^{\prime}$ for $x_{1} \geqslant 1, x_{2} \leqslant 0$. When retailers have inventory $\left(x_{1}, x_{2}\right)$ in period $n$, a unit is reassigned from retailer 1 to retailer 2 if and only if $\gamma_{n-1}\left(x_{1}, x_{2}+1\right) \leqslant b-K^{\prime}$ for $x_{1} \geqslant 1, x_{2} \leqslant-1$.

With some abuse of notation, we continue to call the expected costs and cost differences above as $V_{n}, Y_{n}, \delta_{n}$, and $\gamma_{n}$ in this section. They are different from, but analogous to, those defined in Section 3. One way to check this analogousness is to examine them after setting $h_{1}=0$, in which case the costs and cost differences of this section coincide with those in Section 3. This leads to the question of whether the cost functions of this section can be obtained by setting $h_{1}=0$ in the functions of Section 3 . The answer is yes for recursive functions, which are all of the functions except for (16) and (21). These two functions are related to the costs at the end of a cycle when $n=0$. Since the functions change at $n=0$, we expect that some of our previous results may not hold. Lemma 4 and Theorem 3 provide a formal account of what happens under CHA.

Lemma 4 For $n \geqslant 1, x_{1} \geqslant 1$, and $x_{2} \leqslant 0$,

(i) $\delta_{n}\left(x_{1}, x_{2}\right)$ is non-increasing in $x_{1}: \delta_{n}\left(x_{1}, x_{2}\right) \leqslant$ $\delta_{n}\left(x_{1}-1, x_{2}\right)$,

(ii) $\gamma_{n}\left(x_{1}, x_{2}\right)$ is non-increasing in $x_{1}: \gamma_{n}\left(x_{1}, x_{2}\right) \leqslant$ $\gamma_{\mathrm{n}}\left(x_{1}-1, x_{2}\right)$.

Lemma 4 specifies the monotonicity of $\delta_{n}\left(x_{1}, x_{2}\right)$ and $\gamma_{n}\left(x_{1}, x_{2}\right)$ in $x_{1}$. Thus, as with PHA, the optimal transshipment and reassignment policies with the CHA scheme are also characterized by holdback levels, which is stated by Theorem 3.

Theorem 3 For $x_{i} \geqslant 1$ and $x_{j} \leqslant 0$ when $i, j \in\{1,2\}$ and $i \neq j$, we have the following for each period $n$.

(i) There exists a transshipment holdback level $\widetilde{x}_{i}^{n}\left(x_{j}\right)$ for retailer $i$ such that it is optimal to reject (respectively, accept) the transshipment request when $x_{i} \leqslant \widetilde{x}_{i}^{n}\left(x_{j}\right)$ (respectively, $x_{i}>\widetilde{x}_{i}^{n}\left(x_{j}\right)$ ).

(ii) There exists a reassignment holdback level $\widehat{x}_{i}^{n}\left(x_{j}\right)$ for retailer $i$ such that it is optimal to reject (respectively, accept) the reassignment request when $x_{i} \leqslant \widehat{x}_{i}^{n}\left(x_{j}\right)$ (respectively, $x_{i}>\hat{x}_{i}^{n}\left(x_{j}\right)$ ).

Under CHA, the holdback levels of a retailer can depend on the inventory of the other retailer and they are not necessarily monotone over time. On the other hand, in the case of PHA, holdback levels are monotone over time; see Theorem 1(ii) and 1(iv). This monotonicity is instrumental for establishing that the inventory level remains below the holdback level if it falls below that level. It is a key ingredient of the argument, in Theorem 2 and before, that leads to the unnecessity of reassignments.

Without monotone holdback levels under CHA, reassignments may be necessary to minimize cost. Namely, 
because of the absence of monotonicity in $n$ for either the transshipment or the reassignment holdback levels, properties such as those stated by Lemmas 2 and 3 cannot be obtained. Accordingly, there is not a nice and strong conclusion about the relation between transshipment and reassignment decisions such as that given by Theorem 2 . Thus reassignments may decrease the total cycle cost under CHA.

\section{Numerical analyses to assess benefits of reassignments for multi-retailer systems}

Extension of the optimal transshipment and reassignment policies to multiple $(>2)$ retailers is not straightforward. Archibald (2007) shows that a holdback level-based transshipment policy that is optimal in a two-retailer system is not optimal in a multi-retailer system. This can be proved also in our setting, which includes reassignments. With multiple retailers, the transshipment decision from a retailer with on-hand inventory to a stocked-out retailer relies also on inventory levels at other retailers. This requires tracking inventory levels at all retailers for every transshipment decision and makes it difficult to define the optimal policy structure.

For PHA, to compute costs without fully understanding the policy structure, let $M$ be the number of retailers and $x=\left(x_{1}, x_{2}, \ldots, x_{M}\right)$ be the vector of inventory levels. Similarly, $h$ and $b$ are vectors of the holding costs and backorder costs, respectively. Let $\mathcal{P}(x)$ and $\mathcal{N}(x)$ be the set of indices for retailers with, respectively, positive and negative inventory levels. Let $e_{i}$ denote a unit vector whose $i$ th element is one while all others are zero. Let $e_{i j}=e_{j}-e_{i}$ and $p_{0}=1-\sum_{i=1}^{M} p_{i}$. The cost functions with reassignment for the PHA scheme are $V_{0}^{P}(x)=0$ and

$$
\begin{array}{r}
V_{n}^{P}(x)=p_{0} Y_{n}^{P}(x)+\sum_{m \in \mathscr{P}(x)} p_{m} Y_{n}^{P}\left(x-e_{m}\right) \\
+\sum_{m \notin \mathscr{P}(x)} p_{m} \min \left\{\operatorname { m i n } _ { i \in \mathscr { P } ( x ) } \left\{K^{\prime}+Y_{n}^{P}\left(x-e_{i}\right),\right.\right. \\
\left.\left.Y_{n}^{P}\left(x-e_{m}\right)\right\}\right\}
\end{array}
$$

Table 2 Pseudocode for multiple reassignments with given $V_{n-1}^{\mathrm{C}}$ and $x$.

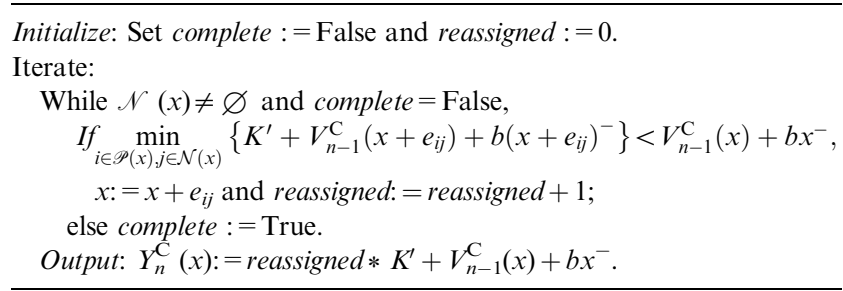

under PHA in multi-retailer systems. Therefore, numerical analyses under PHA are not reported.

The rest of this section focuses only on CHA and illustrates the benefit of reassignments. For this purpose, two separate settings are considered: one with optimal reassignments and another without reassignments. To calculate the total optimal expected cost over $N$ periods, starting with $n=0$ and $V_{0}^{C}(x)=h(x)^{+}$, we use

$$
\begin{array}{r}
V_{n}^{C}(x)=p_{0} Y_{n}^{C}(x)+\sum_{m \in \mathscr{P}(x)} p_{m} Y_{n}^{C}\left(x-e_{m}\right) \\
+\sum_{m \notin \mathscr{P}(x)} p_{m} \min \left\{\operatorname { m i n } _ { i \in \mathscr { P } ( x ) } \left\{K^{\prime}+Y_{n}^{C}\left(x-e_{i}\right),\right.\right. \\
\left.\left.Y_{n}^{C}\left(x-e_{m}\right)\right\}\right\},
\end{array}
$$

and the computation of $Y_{n}^{C}(x)$ in Table 2, which allows for multiple reassignments. For the cost with no reassignments, each $Y_{n}^{C}\left(x_{0}\right)$ in (23) is replaced by $V_{n-1}^{C}\left(x_{0}\right)+$ $b x_{0}^{-}$for $x_{0} \in\left\{x, x-e_{m}, x-e_{i}\right\}$

As in the two-retailer system, there is at most one demand arrival to the multi-retailer system in each period. According to (22) and (23), the cost of transshipping from a retailer with inventory to a stocked-out retailer is compared with the cost of not transshipping. If more than one profitable transshipment alternative are found, the most profitable one is executed. Thus the transshipment decision is made optimally. Similar observations based on Table 2 yield that the reassignment decision is also optimal.

$$
Y_{n}^{P}(x)=\min \left\{\min _{i \in \mathscr{P}(x), j \in \mathcal{N}(x)}\left\{K^{\prime}+V_{n-1}^{P}\left(x+e_{i j}\right)+h\left(x+e_{i j}\right)^{+}+b\left(x+e_{i j}\right)^{-}\right\}, V_{n-1}^{P}(x)+h x^{+}+b x^{-}\right\}
$$

where $x^{+}=\max \{0, x\}$ and $x^{-}=\max \{0,-x\}$ are performed component-wise for vector $x$. For the cost without reassignments, each $Y_{n}^{P}\left(x_{0}\right)$ in (22) is replaced by $V_{n-1}^{P}\left(x_{0}\right)+h x_{0}^{+}+b x_{0}^{-}$for $x_{0} \in\left\{x, x-e_{m}, x-e_{i}\right\}$.

Under PHA, we have numerically compared the costs of multi-retailer systems with and without reassignments using randomly generated instances described below. Failing to find a difference in costs, we conjecture that reassignments are not necessary to obtain the optimal cost
Note that the optimal cost can be computed for the multiretailer case even though a simple optimal policy cannot be identified.

To determine the replenishment quantities, the IM may minimize the expected single-cycle cost, or the sum of discounted cycle costs, or the long-run average cost. Çömez et al (2012a) show that to minimize the expected long-run average cost, it is enough to minimize the holding, 
backorder, and transshipment costs over a single cycle. Thus, in numerical analyses, we minimize the single cycle costs $V_{N}(Q)$ with complete enumeration over replenishment quantities $Q=\left[Q_{1}, Q_{2}, \ldots, Q_{M}\right]$, where $Q_{i} \in\{0, \ldots, N\}$. Then we select the $Q$ that minimizes $V_{N}(Q)$. We illustrate the optimal stocking level and cost calculations for a small size problem instance.

Illustrative example: Let $M=2, N=2, p_{1}=0.3, p_{2}=0.5$, $h_{1}=h_{2}=3, h_{0}=0, b_{1}=b_{2}=4, T=1$, and $K=5$. So, $K^{\prime}=9$. Each retailer should stock at most two units, that is, $Q_{i} \in\{0,1,2\}$ for $i=\{1,2\}$. Starting with $n=0$, a backward induction is used to go from period $n$ to $n+1$. For $n \geqslant 1$, $Y_{n}^{C}\left(x_{1}, x_{2}, x_{b}\right)$ is computed for $x_{1}, x_{2} \in\{0,1,2\}$ and $x_{b} \in\{0, \ldots, 3-n\}$, where $x_{b}$ is the total number of backorders before a potential reassignment. Then, $V_{n}^{C}\left(x_{1}, x_{2}, x_{b}\right)$ is computed for $x_{1}, x_{2} \in\{0,1,2\}$ and $x_{b} \in\{0, \ldots, 2-n\}$, as the number of backorders at the beginning of period $n$ can be at most $2-n$. After all $V_{2}^{C}\left(x_{1}, x_{2}, 0\right)$ values are calculated, the minimum value of $V_{2}^{C}\left(x_{1}, x_{2}, 0\right)$ is selected from all combinations of $x_{1}, x_{2} \in\{0,1,2\}$. In summary, $54 V_{n}^{C}$ 's and $45 Y_{n}^{C,}$ s are computed to find the optimal $V_{2}^{C}$ and $Q_{1}, Q_{2}$. All of the $V_{n}^{C}$,s and $Y_{n}^{C}$, s are reported in Table A1. Some computations are illustrated next.

Compute $V_{0}^{C}\left(x_{1}, x_{2}, x_{b}\right)=3 x_{1}+3 x_{2}$ for $x_{1}, x_{2}, x_{b} \in$ $\{0,1,2\}$.

Compute $Y_{1}^{C}\left(x_{1}, x_{2}, x_{b}\right)$ from $V_{0}^{C}$ as in Table 2 for $x_{1}, x_{2}$, $x_{b} \in\{0,1,2\}$, for example, $Y_{1}^{C}(0,1,1)=\min \{0,1,1\}+4$, $\left.V_{0}^{C}(0,0,0)+9\right\}=\min \{7,9\}=7$.

Compute $V_{1}^{C}\left(x_{1}, x_{2}, x_{b}\right)$ from $Y_{1}^{C}$ as in (23) for $x_{1}, x_{2} \in$ $\{0,1,2\}$ and $x_{b} \in\{0,1\}$, for example, $V_{1}^{C}(0,1,0)=0.3$ $\min \left\{Y_{1}^{C}(0,1,1), \quad Y_{1}^{C}(0,0,0)+9\right\}+0.5 \quad Y_{1}^{C}(0,0,0)+$ $0.2 Y_{1}^{C}(0,1,0)=0.3 \min \{7,9\}+0+0.2 \times 3=2.7$.

Compute $Y_{2}^{C}\left(x_{1}, x_{2}, x_{b}\right)$ from $V_{1}^{C}$ as in Table 2 for $x_{1}$, $x_{2} \in\{0,1,2\}$ and $x_{b} \in\{0,1\}$, for example, $Y_{2}^{C}(0,2,1)=$ $\min \left\{V_{1}^{C}(0,2,1)+4, V_{0}^{C}(0,2,1)+9\right\}=\min \{13.7,11.7\}=11.7$

Compute $V_{2}^{C}\left(x_{1}, x_{2}, 0\right)$ from $Y_{2}^{C}$ as in (23) for $x_{1}, x_{2} \in$ $\{0,1,2\}$, for example, $V_{2}^{C}(0,2,0)=0.3 \min \left\{Y_{2}^{C}(0,2,1)\right.$, $\left.Y_{2}^{C}(0,1,0)+9\right\}+0.5 Y_{2}^{C}(0,1,0)+0.2 \quad Y_{2}^{C}(0,2,0)=0.3$ $\min \{11.7,11.7\}+0.5 \times 2.7+0.2 \times 5.7=6$.

Compute $Q_{1}$ and $Q_{2}$ by minimizing $V_{2}^{C}\left(x_{1}, x_{2}, 0\right)$ for $x_{1}, x_{2} \in\{0,1,2\}$. The optimal replenishment levels are $Q_{1}=Q_{2}=1$ and $V_{2}^{C}(1,1,0)=3.58$.

As the $V_{N}(Q)$ computations should be repeated (in the order of) $N^{M}$ times to obtain the optimal replenishment levels, the computation time increases fast with the number of retailers and the number of periods in a cycle. Thus numerical analyses are conducted with $N=40$ and $M \in\{2, \ldots, 6\}$. Among the previous transshipment studies considering optimal cyclic replenishments and periodic transshipments between multiple retailers, $M=5$ in Archibald (2007) and van Wijk et al (2012), and $M=3$ in Archibald et al (2009 and 2010) for the purpose of numerical analyses.

Parameter values are based on the past studies with similar settings. Çömez et al (2010) and Mangal and
Chandna (2009) are two examples in the transshipment literature that relate their problem parameters with actual data. Çömez et al (2010) select their problem parameters from the automotive industry and other past studies with similar problem scenarios. Data in Mangal and Chandna (2009) come from a bike distribution network in India. A cycle is a month and each cycle has $N=40$ periods. Çömez et al (2010) show that changing $N$ changes holdback policy only slightly. Monthly demand rate at retailer $i$ is $N P_{i} \in(0, N / M)$. Independent of the number of retailers, the maximum monthly demand for an $M$-retailer system is $N=40$ and the minimum is zero.

Among the few studies allowing positive transshipment time, Tagaras and Vlachos (2002) use a transshipment time of 1 day. In our numerical studies, $T$ is between 1 and 9 periods ( 0.75 to 6.75 days when a cycle is 30 days). $T=4$ in our base problem setting. The magnitude of the fixed transportation cost can be assessed relative to the holding cost as $K / h$, because both may depend on the unit product cost. Mangal and Chandna (2009) have $K / h=0.19$. Çömez et al $(2010)$ use $K / h \in[077,10]$. In our numerical analyses, $K / h \in[0.11,5.56]$ and $K / h=0.33$ in our base setting. Similarly, $(N b) / h$ is the backorder cost relative to holding cost over a cycle. In Mangal and Chandna (2009), backorder cost is charged once (not over time) and $(\mathrm{Nb}) /$ $h=2.5$. In our numerical analyses, $(N b) / h \in[0.67,44.45]$ and $(N b) / h=2.67$ in our base setting. In our base setting, $K=20, T=4$, and $N=40$, and retailers are identical so both $h$ and $b$ are scalars with values $h=60$ and $b=4$.

For each $M \in\{2, \ldots 6\}, 100$ problem instances are generated by sampling each parameter from a uniform distribution over the following ranges: $p_{i} \in(0,1 / M)$, $h_{i} \in(9,90), \quad T \in(1,9), \quad K \in(10,50)$, and $b \in(2,10)$ for $i \in$ $\{1, \ldots, M\}$. In each instance, retailers $i$ and $j$ can have different demand probabilities and holding costs, that is, $p_{i} \neq p_{j}$ and $h_{i} \neq h_{j}$, while other parameters $T, K$, and $b$ are the same. With $p_{i}$ uniformly distributed over $(0,1 / M)$, the total expected demand per period is $1 / 2$ in an $M$-retailer system. Since the total demand does not change with $M$, the results for systems with different number of retailers can be compared.

A demand is satisfied by four methods: in-stock (previous replenishment), transshipment, reassignment, and next replenishment. The average percentage of demand satisfied by each of the four methods is in Table 3. The results indicate that when there are more retailers, the IM relies more on transshipments than the other three methods. In general, the average use of reassignments is also increasing in the number of retailers, while it is not monotone. These increases in transshipments and reassignments can be explained by the increasing number of retailers and the independence of demand among these retailers. More independence leads to higher chances of finding a retailer that can accept a transshipment or reassignment request. 
Table 3 Demand fulfillment by four methods

\begin{tabular}{lcccc}
\hline Number of retailers & \multicolumn{3}{c}{ Average percent(\%) of demand fulfilled by four methods } \\
\cline { 2 - 5 } & In-stock & Transshipment & Reassignment & Next replenishment \\
\hline 2 & 86.58 & 3.79 & 0.16 & 9.47 \\
3 & 85.01 & 6.27 & 0.21 & 8.50 \\
4 & 81.72 & 9.05 & 0.33 & 8.90 \\
5 & 79.53 & 11.05 & 0.30 & 8.07 \\
6 & 77.84 & 13.01 & & 8.85 \\
\hline
\end{tabular}
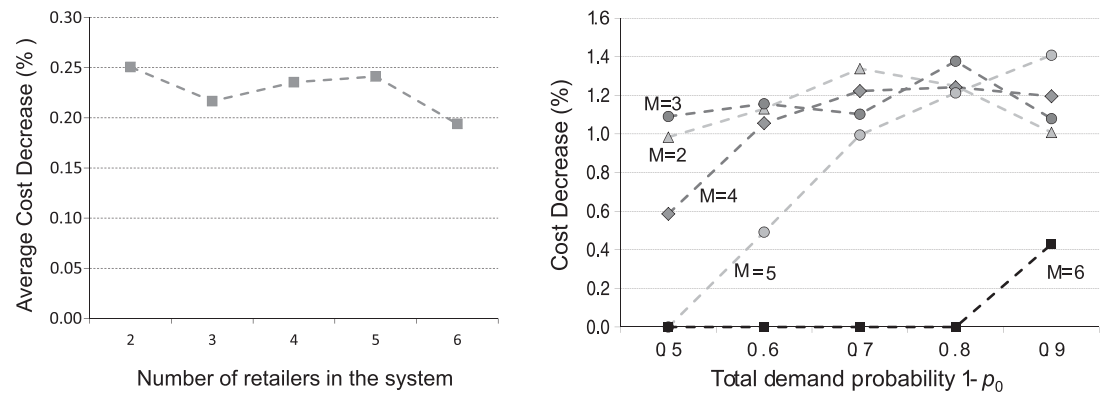

Figure 2 The gap (cost decrease) $\Delta V^{\mathrm{C}}$ between expected costs with and without reassignments. Left: Average gap versus $M$; Right: Gap versus $1-p_{0}$.

Next, the optimal costs $V_{N}^{C, R}$ and $V_{N}^{C, N R}$, respectively with reassignment and with no reassignments, are evaluated. Let $\Delta V^{C}$ denote the cost decrease in the total cycle cost with reassignments under $\mathrm{CHA}$ and it is computed as $\Delta V^{C}=100\left(V^{C, N R}-V^{C, R}\right) / V^{C, N R}$. This decrease also is the gap between $V^{C, N R}$ and $V^{C, R}$. The gap is computed with the same 100 instances for each $M$-retailer system used to obtain Table 3. In the left panel of Figure 2, the average gap is plotted, which is both small and non-monotone in $M$. Among the 500 tested problems in the left panel of Figure 2,95 per cent of the instances lead to a gap that is less than 1 per cent.

The gap is investigated as the total demand probability $1-p_{0}$ increases from 0.5 to 0.9 in the right panel of Figure 2. In each instance, $K=20, T=4, h_{i}=60, b_{i}=4, p_{i}=\left(1-p_{0}\right)$ / $M$ for $i \in\{1, \ldots, M\}$ and $M \in\{2, \ldots, 6\}$. The highest gap is small at about $1.4 \%$.

Lastly, the sensitivity of the gap to changes in costs (holding $h$, backorder $b$, and transportation $K$ ) and transshipment lead time $T$ is investigated. In Figures 3 and $4, M \in\{2,4,6\}, h_{i}=h$ and $p_{i}=0.7 / M$ for $i \in\{1, \ldots$, $M\}$. In these figures, one of $h, T, K$, and $b$ varies and is shown in the horizontal axis while the other three parameters are fixed at the base setting $h=60, b=4$, $K=20$ and $T=4$. The gap and the percentage of demand satisfied by reassignments are shown, respectively, in top and bottom panels of the figures.

Figure 3 indicates that reassignments are more useful in reducing the cost when $h$ is higher or $b$ is lower. While satisfying backorders, reassignments eliminate excess inventory. So reassignments are used more often and become more valuable when $h$ is higher and inventory levels are lower. But when $h$ increases further, retailers keep significantly low levels of inventory, which reduces their ability to reassign, as the bar chart in the bottom left panel of the figure indicates. In sum, the gap still increases but at a decreasing rate. As $h$ increases, both the total cost $V^{C, N R}$ and the gap $\Delta V^{C}$ increase. This means that $V^{C, R}-V^{C, N R}=$ $V^{C, N R} \Delta V^{C}$ increases faster than either $V^{C, N R}$ or $\Delta V^{C}$. Note that $V^{C, R}-V^{C, N R}$ can be an appropriate measure when budgeting for the logistics expenses of a distribution system.

The effect of $b$ on the gap is more complicated than that of $h$. One could expect that as $b$ increases, the total cost of backordering in a cycle increases. So reassignments that eliminate some backorders could be more beneficial when $b$ is higher. On the other hand, a high $b$ could lead to both high replenishment levels and a large number of transshipments. Hence, backorders, and in turn reassignments, could occur less when $b$ is higher. In Figure 3 , the combined effect of these factors decreases the gap as $b$ increases. So when $b$ is low, reassignments can be valuable to decrease the total cost, but both the number of reassignments and the gap decrease with $b$.

On the other hand, the gap appears to be unimodal as either $K$ or $T$ increases. An increase in $K$ or $T$ raises the cost of each transshipment and increases the number of backorders. Each extra backorder presents at least one and at most $N$ more reassignment opportunities. So despite being non-monotone, the use of reassignments increases in general with rising $K$ or $T$ as shown in Figure 4. 

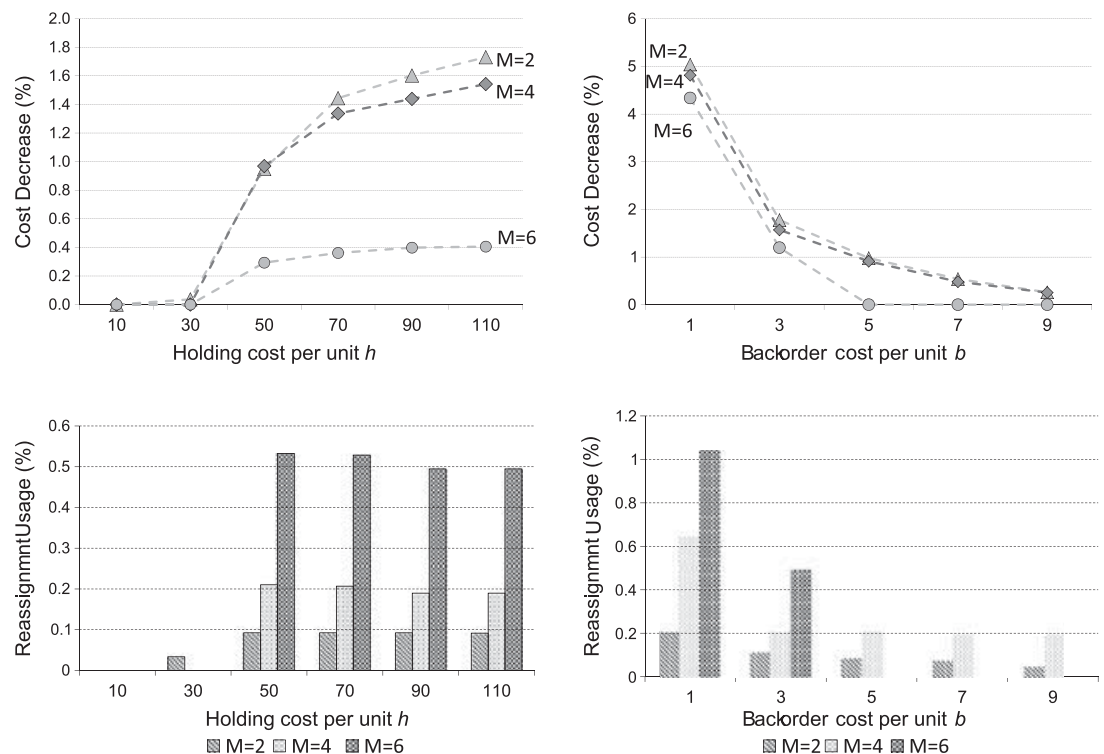

Figure 3 Top panels: The gap (cost decrease) $\Delta V^{\mathrm{C}}$ between expected costs with and without reassignments. Left: Gap versus holding cost $h$; Right: Gap versus backorder cost $b$. Bottom panels: The per cent use of reassignments to satisfy demand. Left: Usage versus holding cost $h$; Right: Usage versus backorder cost $b$.
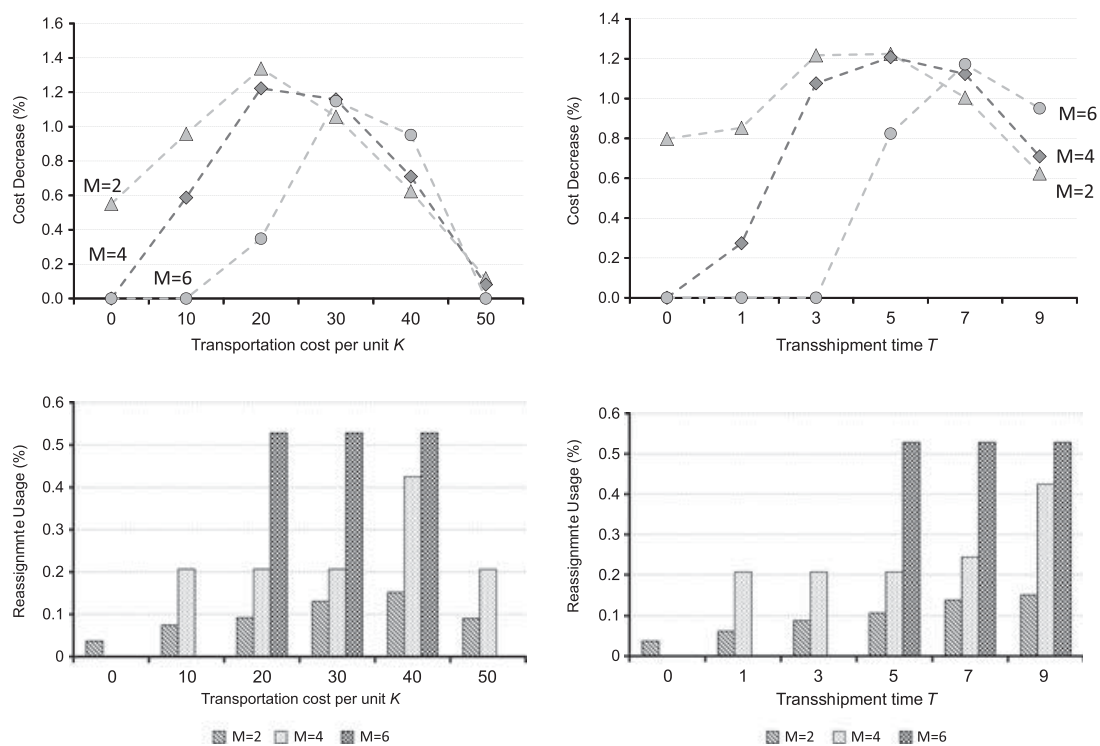

Figure 4 Top panels: The gap (cost decrease) $\Delta V^{\mathrm{C}}$ between expected costs with and without reassignments. Left: Gap versus transportation cost K; Right: Gap versus transshipment time T. Bottom panels: The per cent use of reassignments to satisfy demand. Left: Usage versus transportation cost $K$; Right: Usage versus transshipment time $T$.

However, this increase does not correspond to an increase in the benefit of reassignments as the benefit can be adversely affected by rising $K$ or $T$.

All of the gaps (cost decreases) are less than $2 \%$ in Figure $2-4$, except for $b=1$ in the top right panel of Figure 3. With $b=1$, the cost of backordering throughout a cycle is extremely low, that is, $N b=40<60=h$. These parameters in a newsvendor context give a service level of only $40 \%=(N b) /(N b+h)$. Apart from this extreme case, the no-reassignment policy is an effective heuristic for systems of multiple retailers as long as transshipments and replenishments are optimal.

\section{Conclusions}

In this study, transshipments among retailers that are managed by a central IM are studied. Different from 
previous transshipment studies in the literature, reassignment of inventory to meet backordered demands is explicitly examined. In a two-retailer system, reassignments interestingly turn out to be unnecessary for optimality under periodic holding cost accounting if retailers are transshipping inventory optimally among each other to meet new customer demands. The optimal transshipment policy is based on holdback levels, which are shown to be independent of outstanding backorders. If a retailer has more inventory than the optimal holdback level, inventory is transshipped to the stocked-out retailer in case of a need. Holdback levels are non-decreasing in time, so a cycle is split into acceptance and rejection time windows for a retailer. All transshipment requests are accepted by the retailer within the acceptance window, beyond which no requests are accepted. The length of each window depends on demand realizations and so cannot be determined at the beginning of a cycle.

It is common in the literature that backorder costs are charged period by period for all outstanding backorders. This cost computation requires the IM to keep track of backorders carefully to account for backorder costs over time. Instead of charging backorder costs period by period for all outstanding backorders, when a demand is not met immediately, its total backorder cost until the next replenishment can be charged at once to the cost function. Such a backorder cost computation is possible in our transshipment problem under periodic holding cost accounting, because it is shown that optimal transshipment decisions are independent of outstanding backorders and reassignments are not useful to achieve optimal cost. Although these analytical results cannot be extended to systems of multiple retailers, numerical analyses confirm that reassignments remain unnecessary for these larger systems under periodic holding cost accounting. So once a demand is backordered, it should stay backordered until the next replenishment. These facts are used to streamline backorder cost computations. Simplification of the computations can facilitate implementation of optimal transshipment policies in practice.

Surprisingly, cost accounting can change optimal transshipment and reassignment policies. We show that under cyclic holding cost accounting, while a holdback level-based transshipment policy is still optimal, holdback levels are not monotone in time. Also, under this accounting scheme, reassignments can be necessary for optimality. Necessity of reassignments for optimality brings challenges in implementation such as additional consideration and management of the reassignment process. Thus some practitioners may want to avoid reassignments although they are profitable under cyclic holding cost accounting. Under this accounting scheme, numerical tests were performed to measure the cost improvement provided by reassignments. This cost improvement is very small for systems of multiple retailers. So a no-reassignment policy is very effective also under cyclic holding cost accounting.

The transshipment model studied in this paper can be extended. In the current study, transshipments and reassignments are allowed in single units of inventory, which implicitly assumes no economies of scale in transshipment costs. When reassigning in multiple units is allowed, we expect that results on the unnecessity of reassignments may still hold. The extension of the current model to allow reassignments in multiple units may require treating a single reassignment request for multiple units as a series of multiple reassignment requests, each for one unit. If each of these reassignment requests are rejected in the optimal policy, then the single reassignment request for multiple units should also be rejected. On the other hand, if there are economies of scale in transportation costs, our results may not hold anymore. Modelling fixed transshipment costs along with multiple transshipment opportunities in an order cycle is an interesting open research question.

\section{References}

Anupindi R, Bassok Y and Zemel E (2001). A general framework for the study of decentralized distribution systems. Manufacturing \& Service Operations Management 3(4): 349-368.

Archibald TW (2007). Modelling replenishment and transshipment decisions in periodic review multilocation inventory systems. Journal of the Operational Research Society 58(7): 948-956.

Archibald TW, Sassen SAE and Thomas LC (1997). An optimal policy for a two depot inventory problem with stock transfer. Management Science 43(2): 173-183.

Archibald TW, Black DP and Glazebrook KD (2009). An index heuristic for transshipment decisions in multi-location inventory systems based on a pairwise decomposition. European Journal of Operational Research 192(1): 69-78.

Archibald TW, Black DP and Glazebrook KD (2010). The use of simple calibrations of individual locations in making transshipment decisions in a multi-location inventory network. Journal of the Operational Research Society 61(2): 294-305.

Çömez N, Stecke KE and Çakanyıldırım M (2010). Meeting correlated spare part demands with optimal transshipments. International Journal of Strategic Decision Sciences 1(2): 1-27.

Çömez N, Stecke KE and Çakanyıldırım M (2012a). Multiple incycle transshipments with positive delivery times. Production and Operations Management 21(2): 378-395.

Çömez N, Stecke KE and Çakanyıldırım M (2012b). In-season transshipments among competitive retailers. Manufacturing \& Service Operations Management 14(2): 290-300.

Grahovac J and Chakravarty A (2001). Sharing and lateral transshipment of inventory in a supply chain with expensive low-demand items. Management Science 47(4): 579-594.

Granot D and Sošić G (2003). A three-stage model for a decentralized distribution system of retailers. Operations Research 51(5): 771-784.

$\mathrm{Hu}$ X, Duenyas I and Kapuscinski R (2007). Existence of coordinating transshipment prices in a two-location inventory model. Management Science 53(8): 1289-1302.

Iravani SMR, Liu T, Luangkesorn KL and Simchi-Levi D (2007). A produce-to-stock system with advance demand information and secondary customers. Naval Research Logistics 54(3): 331-345. 
Kukreja A, Schmidt CP and Miller DM (2001). Stocking decisions for low-usage items in a multilocation inventory system. Management Science 47(10): 1371-1383.

Lee TC and Hersh M (1993). A model for dynamic airline seat inventory control with multiple seat bookings. Transportation Science 27(3): 252-265.

Mangal D and Chandna P (2009). Inventory control in supply chain through lateral shipments - A case study in Indian industry. International Journal of Engineering 3(5): 443-457.

Rudi N, Kapur S and Pyke DF (2001). A two-location inventory model with transshipment and local decision making. Management Science 47(12): 1668-1680.

Sošić G (2006). Transshipment of inventories among retailers: Myopic versus farsighted stability. Management Science 52(10): 1493-1508.

Tagaras G and Cohen MA (1992). Pooling in two-location inventory systems with non-negligible replenishment lead times. Management Science 38(8): 1067-1083.

Tagaras G and Vlachos D (2002). Effectiveness of stock transshipment under various demand distributions and nonnegligible transshipment times. Production Operations Management 11(2): 183-198.

Talluri K and van Ryzin G (2004). Revenue management under a general discrete choice model of consumer behavior. Management Science 50(1): 15-33.

van Wijk ACC, Adan IJBF and van Houtum GJ (2012). Approximate evaluation of multi-location inventory models with lateral transshipments and hold-back levels. European Journal of Operational Research 218(3): 624-635.

Zhao H, Desphande V and Ryan JK (2005). Inventory sharing and rationing in decentralized dealer networks. Management Science 51(4): 531-547.

Zhao H, Desphande V and Ryan JK (2006). Emergency transshipment in decentralized dealer networks: When to send and accept transshipment requests. Naval Research Logistics 53(6): 547-567.

Zhao H, Ryan JK and Desphande V (2008). Optimal dynamic production and inventory transshipment policies for a two-location make-to-stock system. Operations Research 56(2): 400-410.

Zhao X and Atkins D (2009). Transshipment between competing retailers. IIE Transactions 41(8): 665-676. 


\section{Appendix}

The following result is used in many intermediate steps of the proofs. We call it a proposition as it is more fundamental than the lemmas, which apply only to our transshipment context.

Proposition 1 For any four real numbers $a, b, c$, and $d$,

$$
\begin{aligned}
\min \{a-c, b-d\} & \leqslant \min \{a, b\}-\min \{c, d\} \\
& \leqslant \max \{a-c, b-d\} .
\end{aligned}
$$

\section{Proof}

$$
\begin{aligned}
\min & \{a, b\}-\min \{c, d\} \\
\quad & =\min \{a, b\}+\max \{-c,-d\} \\
& =\min \{a+\max \{-c,-d\}, b+\max \{-c,-d\}\} \\
& \geqslant \min \{a-c, b-d\}, \\
\min & \{a, b\}-\min \{c, d\} \\
\quad & =\min \{a, b\}+\max \{-c,-d\} \\
& =\max \{-c+\min \{a, b\},-d+\min \{a, b\}\} \\
& \leqslant \max \{a-c, b-d\} .
\end{aligned}
$$

\section{Proofs of Lemmas}

Proofs of Lemma 1 (i)-(ii): (i) and (ii) are proved simultaneously by an induction on $n$. As the induction hypothesis, assume that both (i) and (ii) hold for $n-1$.

We now prove that $\delta_{n}\left(x_{1}, x_{2}\right)$ is non-increasing in $x_{1}$ for $x_{1} \geqslant 0, x_{2} \leqslant 0$ by using the induction hypothesis that $\gamma_{n-1}\left(x_{1}, x_{2}\right)$ is non-increasing in $x_{1}$ for $x_{2} \leqslant 0$. The induction begins with $n=0$, where $\gamma_{0}(\cdot, \cdot)=0$. The proof specializes for four cases: $\left[x_{1}=1, x_{2} \leqslant 0\right],\left[x_{1} \geqslant 1, x_{2}=0\right],\left[x_{1}=2\right.$, $\left.x_{2} \leqslant-1\right]$, and $\left[x_{1} \geqslant 3, x_{2} \leqslant-1\right]$.

Case 1: $\left[x_{1}=1, x_{2} \leqslant 0\right]$. From (9) and (10),

$$
\begin{aligned}
\delta_{n}\left(0, x_{2}\right)- & \delta_{n}\left(1, x_{2}\right) \\
= & \gamma_{n-1}\left(0, x_{2}\right)-\gamma_{n-1}\left(1, x_{2}\right) \\
& +\min \left\{b+h_{1}, K^{\prime}+\gamma_{n-1}\left(1, x_{2}\right)\right\} \\
= & \min \{b+h_{1}+\underbrace{\gamma_{n-1}\left(0, x_{2}\right)-\gamma_{n-1}\left(1, x_{2}\right)}_{\geqslant 0}, K^{\prime}+\underbrace{\gamma_{n-1}\left(0, x_{2}\right)}_{=0}\}
\end{aligned}
$$$$
\geqslant 0 \text {. }
$$

For $x_{1}, x_{2} \leqslant 0, \gamma_{n}\left(x_{1}, x_{2}\right)=V_{n}\left(x_{1}-1, x_{2}\right)-V_{n}\left(x_{1}, x_{2}-1\right)=$ 0 , as the total cost depends only on the total backorder $x_{1}+x_{2}-1$, which follows from combining (3), (4), and (7). $\gamma_{n}\left(x_{1}, x_{2}\right)=0$ implies that $\delta_{n}\left(x_{1}, x_{2}\right)=0$ for $x_{1}, x_{2} \leqslant 0$ from (10).
Case 2: $\left[x_{1} \geqslant 1\right.$ and $\left.x_{2}=0\right]$. From (9)

$$
\begin{aligned}
\delta_{n}\left(x_{1}, 0\right)- & \delta_{n}\left(x_{1}+1,0\right) \\
= & \gamma_{n-1}\left(x_{1}, 0\right)-\gamma_{n-1}\left(x_{1}+1,0\right) \\
& -\min \left\{b+h_{1}, K^{\prime}+\gamma_{n-1}\left(x_{1}, 0\right)\right\} \\
& +\min \left\{b+h_{1}, K^{\prime}+\gamma_{n-1}\left(x_{1}+1,0\right)\right\} \\
\geqslant & \gamma_{n-1}\left(x_{1}, 0\right)-\gamma_{n-1}\left(x_{1}+1,0\right) \\
& +\min \{0, \underbrace{\gamma_{n-1}\left(x_{1}+1,0\right)-\gamma_{n-1}\left(x_{1}, 0\right)}_{\leqslant 0}\} \\
= & 0 .
\end{aligned}
$$

The inequality above results from Proposition 1 and (A.1) follows from the induction hypothesis

Case 3: $\left[x_{1}=2, x_{2} \leqslant-1\right]$. Using (8) and (9),

$$
\begin{aligned}
\delta_{n}(1, & \left.x_{2}\right)-\delta_{n}\left(2, x_{2}\right) \\
= & \gamma_{n-1}\left(1, x_{2}\right)-\gamma_{n-1}\left(2, x_{2}\right)+b+h_{1} \\
& -\min \left\{b+h_{1}, K^{\prime}+\gamma_{n-1}\left(1, x_{2}\right)\right\} \\
& -\min \left\{b+h_{1}, K^{\prime}+\gamma_{n-1}\left(1, x_{2}+1\right)\right\} \\
& +\min \left\{b+h_{1}, K^{\prime}+\gamma_{n-1}\left(2, x_{2}\right)\right\} \\
\geqslant & \gamma_{n-1}\left(1, x_{2}\right)-\gamma_{n-1}\left(2, x_{2}\right)+b+h_{1} \\
& \quad-\min \left\{b+h_{1}, K^{\prime}+\gamma_{n-1}\left(1, x_{2}+1\right)\right\} \\
& \left.+\min \{0, \underbrace{\gamma_{n-1}\left(2, x_{2}\right)-\gamma_{n-1}\left(1, x_{2}\right)}_{\leqslant 0}\} \quad \text { (A.2 }\right) \quad \text { (A.3) } \\
& \quad b+h_{1}-\min \left\{b+h_{1}, K^{\prime}+\gamma_{n-1}\left(1, x_{2}+1\right)\right\} \\
\geqslant & 0 .
\end{aligned}
$$

Equation (A.2) is by Proposition 1 and (A.3) follows from the induction hypothesis.

Case 4: $\left[x_{1} \geqslant 3\right.$ and $\left.x_{2} \leqslant-1\right]$. From (8),

$$
\begin{aligned}
& \delta_{n}\left(x_{1}-1, x_{2}\right)-\delta_{n}\left(x_{1}, x_{2}\right) \\
& =\gamma_{n-1}\left(x_{1}-1, x_{2}\right)-\gamma_{n-1}\left(x_{1}, x_{2}\right) \\
& +\min \left\{b+h_{1}, K^{\prime}+\gamma_{n-1}\left(x_{1}-2, x_{2}+1\right)\right\} \\
& -\min \left\{b+h_{1}, K^{\prime}+\gamma_{n-1}\left(x_{1}-1, x_{2}\right)\right\} \\
& -\min \left\{b+h_{1}, K^{\prime}+\gamma_{n-1}\left(x_{1}-1, x_{2}+1\right)\right\} \\
& +\min \left\{b+h_{1}, K^{\prime}+\gamma_{n-1}\left(x_{1}, x_{2}\right)\right\} \\
& \geqslant \gamma_{n-1}\left(x_{1}-1, x_{2}\right)-\gamma_{n-1}\left(x_{1}, x_{2}\right) \\
& +\min \{0, \underbrace{\gamma_{n-1}\left(x_{1}-2, x_{2}+1\right)-\gamma_{n-1}\left(x_{1}-1, x_{2}+1\right)}_{\geqslant 0}\} \\
& +\min \{0, \underbrace{\gamma_{n-1}\left(x_{1}, x_{2}\right)-\gamma_{n-1}\left(x_{1}-1, x_{2}\right)}_{\leqslant 0}\}=0 \text {. }
\end{aligned}
$$


The inequality above is from Proposition 1 and (A.4) follows from the induction hypothesis. This completes the proof for non-increasing $\delta_{n}\left(x_{1}, x_{2}\right)$ in $x_{1}$, if $\gamma_{n-1}\left(x_{1}, x_{2}\right)$ is non-increasing in $x_{1}$.

We now prove that $\gamma_{n}\left(x_{1}, x_{2}\right)$ is non-increasing in $x_{1}$ by using the recently proved fact that $\delta_{n}\left(x_{1}, x_{2}\right)$ is nonincreasing in $x_{1}$ as $\gamma_{0}=0$. As induction hypothesis, suppose that $\delta_{n}\left(x_{1}, x_{2}\right)$ is non-increasing in $x_{1}$ for $x_{1} \geqslant 1$ and $x_{2} \leqslant 0$. This hypothesis is true for $n=1$. The proof specializes for three cases: $\left[x_{1}=1\right],\left[x_{1}=2\right]$, and $\left[x_{1} \geqslant 3\right]$.

Case 1: $\left[x_{1}=1\right]$. From (12) and (13),

$$
\begin{aligned}
\gamma_{n}\left(0, x_{2}\right)-\gamma_{n}\left(1, x_{2}\right) & \\
= & p_{1}\left(\delta_{n}\left(-1, x_{2}\right)-\delta_{n}\left(0, x_{2}\right)\right) \\
& +\left(1-p_{1}-p_{2}\right)\left(\delta_{n}\left(0, x_{2}\right)-\delta_{n}\left(1, x_{2}\right)\right) \\
& +p_{2}\left[\delta_{n}\left(0, x_{2}-1\right)-\delta_{n}\left(1, x_{2}-1\right)\right. \\
& \left.\quad+\min \left\{0, K^{\prime}+\delta_{n}\left(1, x_{2}-1\right)\right\}\right] \\
\geqslant & p_{1}\left(\delta_{n}\left(-1, x_{2}\right)-\delta_{n}\left(0, x_{2}\right)\right) \\
& +\left(1-p_{1}-p_{2}\right)\left(\delta_{n}\left(0, x_{2}\right)-\delta_{n}\left(1, x_{2}\right)\right) \\
& +p_{2} \min \left\{\delta_{n}\left(0, x_{2}-1\right)-\delta_{n}\left(1, x_{2}-1\right), K^{\prime}\right. \\
& +\underbrace{\delta_{n}\left(0, x_{2}-1\right)}_{=0}\}
\end{aligned}
$$

$\geqslant 0$.

This follows from the induction hypothesis and $\delta_{n}\left(x_{1}, x_{2}\right)$ $=0$ for $x_{1}, x_{2} \leqslant 0$, so that each of the three terms in summation are non-negative.

Case 2: $\left[x_{1}=2\right]$. From (11) and (12)

$$
\begin{aligned}
& \gamma_{n}\left(1, x_{2}\right)-\gamma_{n}\left(2, x_{2}\right) \\
& =p_{1}\left(\delta_{n}\left(0, x_{2}\right)-\delta_{n}\left(1, x_{2}\right)\right) \\
& +\left(1-p_{1}-p_{2}\right)\left(\delta_{n}\left(1, x_{2}\right)-\delta_{n}\left(2, x_{2}\right)\right) \\
& +p_{2}\left(\delta_{n}\left(1, x_{2}-1\right)-\delta_{n}\left(2, x_{2}-1\right)\right) \\
& -p_{2}\left[\min \left\{0, K^{\prime}+\delta_{n}\left(1, x_{2}-1\right)\right\}\right. \\
& \quad+\min \left\{0, K^{\prime}+\delta_{n}\left(1, x_{2}\right)\right\} \\
& \left.\quad-\min \operatorname{big}\left\{0, K^{\prime}+\delta_{n}\left(2, x_{2}-1\right)\right\}\right]
\end{aligned}
$$

$$
\begin{aligned}
& \geqslant p_{1}\left(\delta_{n}\left(0, x_{2}\right)-\delta_{n}\left(1, x_{2}\right)\right) \\
& +\left(1-p_{1}-p_{2}\right)\left(\delta_{n}\left(1, x_{2}\right)-\delta_{n}\left(2, x_{2}\right)\right) \\
& +p_{2}\left[\delta_{n}\left(1, x_{2}-1\right)-\delta_{n}\left(2, x_{2}-1\right)\right. \\
& \quad-\min \left\{0, K^{\prime}+\delta_{n}\left(1, x_{2}\right)\right\} \\
& \left.\quad+\min \{0, \underbrace{\delta_{n}\left(2, x_{2}-1\right)-\delta_{n}\left(1, x_{2}-1\right)}_{\leqslant 0}\}\right] \\
& =p_{1}\left(\delta_{n}\left(0, x_{2}\right)-\delta_{n}\left(1, x_{2}\right)\right) \\
& +\left(1-p_{1}-p_{2}\right)\left(\delta_{n}\left(1, x_{2}\right)-\delta_{n}\left(2, x_{2}\right)\right) \\
& -p_{2} \underbrace{\min \left\{0, K^{\prime}+\delta_{n}\left(1, x_{2}\right)\right\}}_{\leqslant 0} \geqslant 0 .
\end{aligned}
$$

Equation (A.5) is obtained by using Proposition 1 and (A.6) follows from the induction hypothesis.

Case 3: $\left[x_{1} \geqslant 3\right]$. From (11)

$$
\begin{aligned}
& \gamma_{n}\left(x_{1}-1, x_{2}\right)-\gamma_{n}\left(x_{1}, x_{2}\right) \\
& =p_{1}\left(\delta_{n}\left(x_{1}-2, x_{2}\right)-\delta_{n}\left(x_{1}-1, x_{2}\right)\right) \\
& +\left(1-p_{1}-p_{2}\right)\left(\delta_{n}\left(x_{1}-1, x_{2}\right)-\delta_{n}\left(x_{1}, x_{2}\right)\right) \\
& +p_{2}\left[\delta_{n}\left(x_{1}-1, x_{2}-1\right)-\delta_{n}\left(x_{1}, x_{2}-1\right)\right. \\
& +\min \left\{0, K^{\prime}+\delta_{n}\left(x_{1}-2, x_{2}\right)\right\} \\
& -\min \left\{0, K^{\prime}+\delta_{n}\left(x_{1}-1, x_{2}-1\right)\right\} \\
& -\min \left\{0, K^{\prime}+\delta_{n}\left(x_{1}-1, x_{2}\right)\right\} \\
& \left.+\min \left\{0, K^{\prime}+\delta_{n}\left(x_{1}, x_{2}-1\right)\right\}\right] \\
& \geqslant p_{1}\left(\delta_{n}\left(x_{1}-2, x_{2}\right)-\delta_{n}\left(x_{1}-1, x_{2}\right)\right) \\
& +\left(1-p_{1}-p_{2}\right)\left(\delta_{n}\left(x_{1}-1, x_{2}\right)-\delta_{n}\left(x_{1}, x_{2}\right)\right) \\
& +p_{2}\left[\delta_{n}\left(x_{1}-1, x_{2}-1\right)-\delta_{n}\left(x_{1}, x_{2}-1\right)\right. \\
& +\min \{0, \underbrace{\delta_{n}\left(x_{1}-2, x_{2}\right)-\delta_{n}\left(x_{1}-1, x_{2}\right)}_{\geqslant 0}\} \\
& \left.+\min \{0, \underbrace{\delta_{n}\left(x_{1}, x_{2}-1\right)-\delta_{n}\left(x_{1}-1, x_{2}-1\right)}_{\leqslant 0}\}\right] \\
& =p_{1}\left(\delta_{n}\left(x_{1}-2, x_{2}\right)-\delta_{n}\left(x_{1}-1, x_{2}\right)\right) \\
& +\left(1-p_{1}-p_{2}\right)\left(\delta_{n}\left(x_{1}-1, x_{2}\right)-\delta_{n}\left(x_{1}, x_{2}\right)\right) \geqslant 0 \text {. }
\end{aligned}
$$

Equation (A.7) is obtained by using Proposition 1. The rest follows from the induction hypothesis. This completes the proof that if $\delta_{n}\left(x_{1}, x_{2}\right)$ is nonincreasing in $x_{1}$, then $\gamma_{n}\left(x_{1}, x_{2}\right)$ is also nonincreasing in $x_{1}$. 
(iii) - (iv): The proof is done for (iii) and (iv) together. To start the induction, we establish that $\gamma_{1}\left(x_{1}, x_{2}\right) \leqslant \gamma_{0}\left(x_{1}\right.$, $\left.x_{2}\right)$. Since $\gamma_{0}\left(x_{1}, x_{2}\right)=0$, it suffices to show that $\gamma_{1}\left(x_{1}\right.$, $\left.x_{2}\right) \leqslant 0$. For $n=1$,

$$
\begin{gathered}
\delta_{1}\left(x_{1}, x_{2}\right)=0, \quad x_{1}, x_{2} \leqslant 0 . \\
\delta_{1}\left(x_{1}, x_{2}\right)=-\min \left\{b+h_{1}, K^{\prime}\right\}, \\
x_{1} \geqslant 1, x_{2}=0 \text { or } x_{1}=1, x_{2} \leqslant-1 . \\
\delta_{1}\left(x_{1}, x_{2}\right)=-\left(b+h_{1}\right), \quad x_{1} \geqslant 2, x_{2} \leqslant-1 .
\end{gathered}
$$

For $x_{2} \leqslant 0$,

$$
\begin{aligned}
\gamma_{1}\left(x_{1}, x_{2}\right)= & 0, \quad x_{1} \leqslant 0 . \\
\gamma_{1}\left(1, x_{2}\right)= & \left(1-p_{1}-p_{2}\right) \delta_{1}\left(1, x_{2}\right) \\
& +p_{2}\left(\delta_{1}\left(1, x_{2}-1\right)-\min \left\{0, K^{\prime}+\delta_{1}\left(1, x_{2}-1\right)\right\}\right), \\
= & -\left(1-p_{1}\right) \min \left\{b+h_{1}, K^{\prime}\right\} \\
& -p_{2} \min \left\{0, K^{\prime}-\min \left\{b+h_{1}, K^{\prime}\right\}\right\} \leqslant 0, \quad(\text { A. } 11)
\end{aligned}
$$

where (A.11) follows by using (A.9). Next, $\gamma_{1}\left(x_{1}, x_{2}\right) \leqslant 0$ is extended to $x_{1} \geqslant 2$.

$$
\begin{aligned}
\gamma_{1}\left(x_{1}, x_{2}\right)= & p_{1} \delta_{1}\left(x_{1}-1, x_{2}\right)+\left(1-p_{1}-p_{2}\right) \delta_{1}\left(x_{1}, x_{2}\right) \\
+ & +p_{2}\left[\delta_{1}\left(x_{1}, x_{2}-1\right)\right. \\
& +\min \left\{0, K^{\prime}+\delta_{1}\left(x_{1}-1, x_{2}\right)\right\} \\
& \left.-\min \left\{0, K^{\prime}+\delta_{1}\left(x_{1}, x_{2}-1\right)\right\}\right] \\
= & p_{1} \delta_{1}\left(x_{1}-1, x_{2}\right)+\left(1-p_{1}-p_{2}\right) \delta_{1}\left(x_{1}, x_{2}\right) \\
+ & {\left[p _ { 2 } \left[-\min \left\{b+h_{1}, K^{\prime}\right\}\right.\right.} \\
& +\underbrace{\min \left\{0, K^{\prime}+\delta_{1}\left(x_{1}-1, x_{2}\right)\right\}}_{\leqslant 0}]
\end{aligned}
$$$$
\leqslant 0 \text {. }
$$

Equation (A.12) is obtained by replacing $\delta_{1}\left(x_{1}, x_{2}-1\right)$ with $-\left(b+h_{1}\right)$ from (A.10). The result follows from the non-positivity of $\delta_{1}\left(x_{1}-1, x_{2}\right)$ and $\delta_{1}\left(x_{1}, x_{2}\right)$ in (A.8)(A.10). This completes the proof for $\gamma_{1}\left(x_{1}, x_{2}\right) \leqslant \gamma_{0}\left(x_{1}, x_{2}\right)$ for $x_{1} \geqslant 0$ and $x_{2} \leqslant 0$.

To prove $\delta_{n+1}\left(x_{1}, x_{2}\right) \leqslant \delta_{n}\left(x_{1}, x_{2}\right)$ for $n \geqslant 1$, assume that $\gamma_{n}\left(x_{1}, x_{2}\right) \gamma_{n-1}\left(x_{1}, x_{2}\right)$ for $x_{1} \geqslant 0$ and $x_{2} \leqslant 0$. For $x_{1}, x_{2} \leqslant 0$, from (10), $\delta_{n+1}\left(x_{1}, x_{2}\right)=\delta_{n}\left(x_{1}, x_{2}\right)=0$. Now this inequality is established for other values of $x_{1}$ and $x_{2}$ by considering the following two cases.

Case 1: $\left[x_{1} \geqslant 1, x_{2}=0\right.$ or $\left.x_{1}=1, x_{2}-1\right]$. From (9),

$$
\begin{aligned}
\delta_{n+1} & \left(x_{1}, x_{2}\right)-\delta_{n}\left(x_{1}, x_{2}\right) \\
= & \gamma_{n}\left(x_{1}, x_{2}\right)-\gamma_{n-1}\left(x_{1}, x_{2}\right)-\min \left\{b+h_{1}, K^{\prime}+\gamma_{n}\left(x_{1}, x_{2}\right)\right\} \\
& +\min \left\{b+h_{1}, K^{\prime}+\gamma_{n-1}\left(x_{1}, x_{2}\right)\right\}
\end{aligned}
$$

$$
\begin{aligned}
\leqslant & \gamma_{n}\left(x_{1}, x_{2}\right)-\gamma_{n-1}\left(x_{1}, x_{2}\right) \\
& +\max \{0, \underbrace{\gamma_{n-1}\left(x_{1}, x_{2}\right)-\gamma_{n}\left(x_{1}, x_{2}\right)}_{\geqslant 0}\}=0 .
\end{aligned}
$$

This follows by first applying Proposition 1 and then from the induction hypothesis.

Case 2: $\left[x_{1} \geqslant 2, x_{2} \leqslant-1\right]$. From (8),

$$
\begin{aligned}
\delta_{n+1}( & \left.x_{1}, x_{2}\right)-\delta_{n}\left(x_{1}, x_{2}\right) \\
= & \gamma_{n}\left(x_{1}, x_{2}\right)-\gamma_{n-1}\left(x_{1}, x_{2}\right) \\
& +\min \left\{b+h_{1}, K^{\prime}+\gamma_{n}\left(x_{1}-1, x_{2}+1\right)\right\} \\
& -\min \left\{b+h_{1}, K^{\prime}+\gamma_{n}\left(x_{1}, x_{2}\right)\right\} \\
& -\min \left\{b+h_{1}, K^{\prime}+\gamma_{n-1}\left(x_{1}-1, x_{2}+1\right)\right\} \\
& +\min \left\{b+h_{1}, K^{\prime}+\gamma_{n-1}\left(x_{1}, x_{2}\right)\right\} \\
\leqslant & \gamma_{n}\left(x_{1}, x_{2}\right)-\gamma_{n-1}\left(x_{1}, x_{2}\right) \\
& +\max \{0, \underbrace{\gamma_{n}\left(x_{1}-1, x_{2}+1\right)-\gamma_{n-1}\left(x_{1}-1, x_{2}+1\right)}_{\geqslant 0}\} \\
& +\max \{0, \underbrace{\gamma_{n-1}\left(x_{1}, x_{2}\right)-\gamma_{n}\left(x_{1}, x_{2}\right)}\}=0 .
\end{aligned}
$$

This completes the proof of the monotonicity of $\delta_{n}$ in $n$.

To prove the monotonicity of $\gamma_{n}$, assume that $\delta_{n+1}\left(x_{1}\right.$, $\left.x_{2}\right) \leqslant \delta_{n}\left(x_{1}, x_{2}\right)$ for $x_{1} \geqslant 0, x_{2} \leqslant 0$, and $n \geqslant 1$. For $x_{1}, x_{2} \leqslant 0$, from (13), $\gamma_{n+1}\left(x_{1}, x_{2}\right)=\gamma_{n}\left(x_{1}, x_{2}\right)=0$. This inequality is established for other values of $x_{1}$ and $x_{2}$ by considering the following two cases.

Case 1: $\left[x_{1}=1, x_{2} \leqslant 0\right]$. From (12),

$$
\begin{aligned}
\gamma_{n+1}\left(1, x_{2}\right)- & \gamma_{n}\left(1, x_{2}\right) \\
= & \left(1-p_{1}-p_{2}\right)\left(\delta_{n+1}\left(1, x_{2}\right)-\delta_{n}\left(1, x_{2}\right)\right) \\
+ & p_{2}\left[\delta_{n+1}\left(1, x_{2}-1\right)-\delta_{n}\left(1, x_{2}-1\right)\right. \\
& -\min \left\{0, K^{\prime}+\delta_{n+1}\left(1, x_{2}-1\right)\right\} \\
& \left.+\min \left\{0, K^{\prime}+\delta_{n}\left(1, x_{2}-1\right)\right\}\right] \\
\leqslant & \left(1-p_{1}-p_{2}\right)\left(\delta_{n+1}\left(1, x_{2}\right)-\delta_{n}\left(1, x_{2}\right)\right) \\
& +p_{2}\left[\delta_{n+1}\left(1, x_{2}-1\right)-\delta_{n}\left(1, x_{2}-1\right)\right. \\
& +\max \{0, \underbrace{\delta_{n}\left(1, x_{2}-1\right)-\delta_{n+1}\left(1, x_{2}-1\right)}_{\geqslant 0}\} \\
= & \left(1-p_{1}-p_{2}\right)\left(\delta_{n+1}\left(1, x_{2}\right)-\delta_{n}\left(1, x_{2}\right)\right) \leqslant 0 .
\end{aligned}
$$


Case 2: $\left[x_{1} \geqslant 1\right]$. From (11),

$$
\begin{aligned}
& \gamma_{n+1}\left(x_{1}, x_{2}\right)-\gamma_{n}\left(x_{1}, x_{2}\right) \\
& =p_{1}\left(\delta_{n+1}\left(x_{1}-1, x_{2}\right)-\delta_{n}\left(x_{1}-1, x_{2}\right)\right) \\
& +\left(1-p_{1}-p_{2}\right)\left(\delta_{n+1}\left(x_{1}, x_{2}\right)-\delta_{n}\left(x_{1}, x_{2}\right)\right) \\
& +p_{2}\left[\delta_{n+1}\left(x_{1}, x_{2}-1\right)-\delta_{n}\left(x_{1}, x_{2}-1\right)\right. \\
& +\min \left\{0, K^{\prime}+\delta_{n+1}\left(x_{1}-1, x_{2}\right)\right\} \\
& -\min \left\{0, K^{\prime}+\delta_{n+1}\left(x_{1}, x_{2}-1\right)\right\} \\
& -\min \left\{0, K^{\prime}+\delta_{n}\left(x_{1}-1, x_{2}\right)\right\} \\
& \left.+\min \left\{0, K^{\prime}+\delta_{n}\left(x_{1}, x_{2}-1\right)\right\}\right] \\
& \leqslant p_{1}\left(\delta_{n+1}\left(x_{1}-1, x_{2}\right)-\delta_{n}\left(x_{1}-1, x_{2}\right)\right) \\
& +\left(1-p_{1}-p_{2}\right)\left(\delta_{n+1}\left(x_{1}, x_{2}\right)-\delta_{n}\left(x_{1}, x_{2}\right)\right) \\
& +p_{2}\left[\delta_{n+1}\left(x_{1}, x_{2}-1\right)-\delta_{n}\left(x_{1}, x_{2}-1\right)\right. \\
& \quad+\max \{0, \underbrace{\delta_{n+1}\left(x_{1}-1, x_{2}\right)-\delta_{n}\left(x_{1}-1, x_{2}\right)}_{\geqslant 0}\} \\
& +p_{1}\left(\delta_{n+1}\left(x_{1}-1, x_{2}\right)-\delta_{n}\left(x_{1}-1, x_{2}\right)\right) \\
& +\left(1-p_{1}-p_{2}\right)\left(\delta_{n+1}\left(x_{1}, x_{2}\right)-\delta_{n}\left(x_{1}, x_{2}\right)\right) \leqslant 0 .
\end{aligned}
$$

This completes the proof of the monotonicity of $\gamma_{n}$ in $n$, and in turn, the proofs for parts (iii) and (iv) of the lemma.

Proof of Lemma 2 Lemma 2 is proved for parts (A) and (B) simultaneously. The proof is by induction on $n$ and starts by checking the inequalities in (A) and (B) for $\gamma_{0}$ and $\delta_{1}$. Note that $\gamma_{0}\left(x_{1}, x_{2}-1\right)=\gamma_{0}\left(x_{1}, x_{2}\right)=0$. Either $0>b+h_{1}-K^{\prime}$ or $0 \leqslant b+h_{1}-K^{\prime}$. So $\gamma_{0}$ satisfies either (iii) or (iv).

At $n=1, \delta_{1}$ is defined by (A.8)-(A.10). For $x_{1} \leqslant 0$, $\delta_{1}\left(x_{1}, x_{2}-1\right)=\delta_{1}\left(x_{1}, x_{2}\right)=0$, so either (i) or (ii) is satisfied. Similarly, for $x_{1}=1, \delta_{1}\left(1, x_{2}-1\right)=\delta_{1}\left(1, x_{2}\right)=-\min \left\{b+h_{1}\right.$, $\left.K^{\prime}\right\}$. Thus either (i) or (ii) is satisfied. When $x_{1} \geqslant 2$ and $x_{2} \leqslant-1, \delta_{1}\left(x_{1}, x_{2}-1\right)=\delta_{1}\left(x_{1}, x_{2}\right)=-\left(b+h_{1}\right)$, so either (i) or (ii) is satisfied. When $x_{1} \geqslant 2, x_{2}=0$, and $b+h_{1}<K^{\prime}$, $\delta_{1}\left(x_{1}, x_{2}-1\right)=-\left(b+h_{1}\right)=-\min \left\{b+h_{1}, K^{\prime}\right\}=\delta_{1}\left(x_{1}, x_{2}\right)>$ $-K^{\prime}$. So (i) holds. When $x_{1} \geqslant 2, x_{2}=0$, and $b+h_{1} \geqslant K^{\prime}$, $\delta_{1}\left(x_{1}, x_{2}-1\right)=-\left(b+h_{1}\right) \leqslant K^{\prime}=-\min \left\{b+h_{1}, K^{\prime}\right\}=\delta_{1}\left(x_{1}\right.$, $x_{2}$ ). So (ii) holds. Thus $\delta_{1}$ satisfies either (i) or (ii).
When statement (B) is proved for $\gamma_{n}$, the induction hypothesis assumes that statement (A) holds for $\delta_{n}$. On the other hand, when statement (A) is proved for $\delta_{n}$, the induction hypothesis assumes statement (B) for $\gamma_{n-1}$. As in the proof of Lemma 1, when a claim about $\delta_{n}$ in period $n$ is proved, the induction is on the cost $\gamma_{n-1}$. Since Lemma 2 holds for both $\gamma_{0}$ and $\delta_{1}$, induction can start with either of these.

In the proof, two mutually exclusive sets of cases are considered as an induction hypothesis: rejection and acceptance of a request by retailer 1 . When an induction hypothesis is made on $\delta_{n}$, the acceptance case refers to the acceptance of a transshipment request for a new demand. When the induction hypothesis is made on $\gamma_{n}$, the acceptance case refers to the acceptance of a reassignment request for an outstanding backorder. The induction argument addresses first $x_{1}=1$ and then $x_{1} \geqslant 1$.

The main induction steps and cases in the proof are summarized in Figure A1. The initialization steps involve $\gamma_{0}$ and $\delta_{1}$, which are obtained above by using definitions. Two major steps in the proof are proving Statement B in period $n$ by assuming Statement $\mathrm{A}$ in period $n$ (a horizontal step in Figure A1) and proving Statement A in period $n$ by assuming Statement B in period $n-1$ (a diagonal step in Figure A1).

Proof of Statement (B) for $\boldsymbol{x}_{\mathbf{1}}=\mathbf{1}$ : The induction hypothesis is that $\delta_{n}\left(1, x_{2}-1\right)$ and $\delta_{n}\left(1, x_{2}\right)$ satisfy either inequality (i) or (ii). Then the validity of statement (B) is analysed.

Rejection: $\delta_{n}\left(1, x_{2}\right)>-K^{\prime}$. The induction hypothesis provides that $\delta_{n}\left(1, x_{2}-1\right)=\delta_{n}\left(1, x_{2}\right)>-K^{\prime}$, for all $x_{2} \leqslant 0$. Then $\delta_{n}\left(1, x_{2}-2\right)=\delta_{n}\left(1, x_{2}-1\right)>-K^{\prime}$. These inequalities are used in the difference equation below, which is obtained by using (12).

$$
\begin{aligned}
\gamma_{n}\left(1, x_{2}\right)-\gamma_{n}\left(1, x_{2}-1\right) & \\
= & p_{1}\left(\delta_{n}\left(0, x_{2}\right)-\delta_{n}\left(0, x_{2}-1\right)\right) \\
& +\left(1-p_{1}-p_{2}\right)\left(\delta_{n}\left(1, x_{2}\right)-\delta_{n}\left(1, x_{2}-1\right)\right) \\
+ & p_{2}\left[\delta_{n}\left(1, x_{2}-1\right)-\delta_{n}\left(1, x_{2}-2\right)\right. \\
& -\min \{0, \underbrace{K^{\prime}+\delta_{n}\left(1, x_{2}-1\right)}_{>0}\} \\
& \left.++\min \{0, \underbrace{K^{\prime}+\delta_{n}\left(1, x_{2}-2\right)}_{>0}\}\right] \\
=0 . &
\end{aligned}
$$

It is shown in the proof of Lemma 1 that $\delta_{n}\left(x_{1}, x_{2}\right)=0$ for $x_{1}, x_{2} \leqslant 0$. The rest of the result follows from the induction hypothesis. Since $\gamma_{n}\left(1, x_{2}-1\right)=\gamma_{n}\left(1, x_{2}\right)$, either 


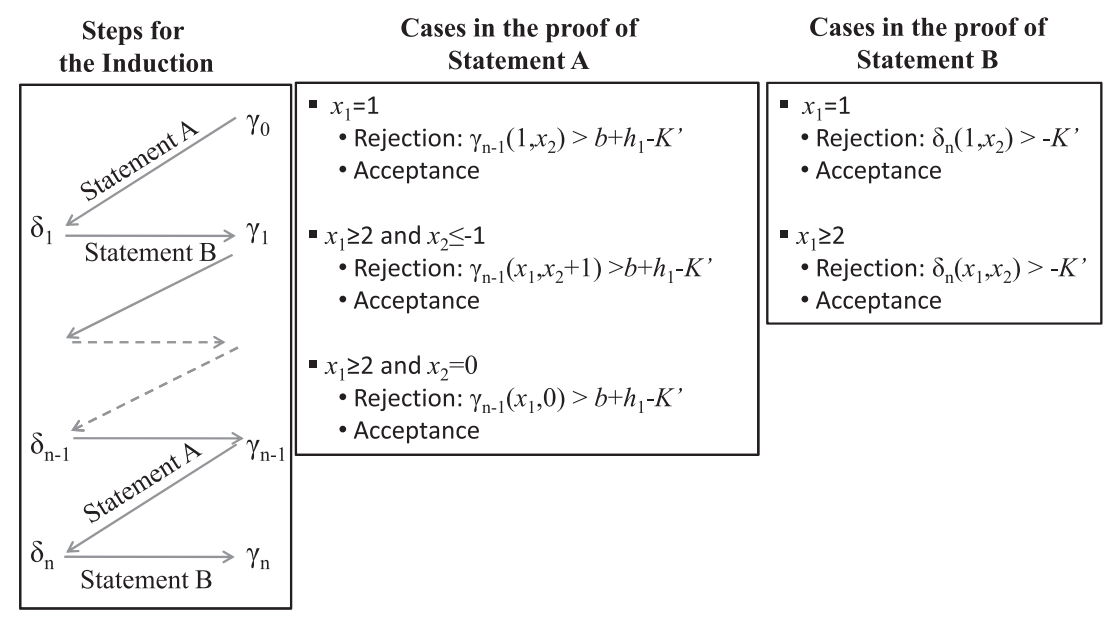

Figure A1 Summary of the main steps and cases in the proof of Lemma 2.

(iii) or (iv) must be true. This completes the inductive argument for $x_{1}=1$ for the rejection case.

Acceptance: $\delta_{n}\left(1, x_{2}\right) \leqslant-K^{\prime}$. The induction hypothesis provides that $\delta_{n}\left(1, x_{2}-1\right) \delta_{n}\left(1, x_{2}\right) \leqslant-K^{\prime}$ and $\delta_{n}(1$, $\left.x_{2}-2\right) \leqslant \delta_{n}\left(1, x_{2}-1\right) \leqslant-K^{\prime}$ for all $x_{2} \leqslant 0$. These inequalities are used in the difference equation below.

$$
\left.\begin{array}{rl}
\gamma_{n}\left(1, x_{2}\right)-\gamma_{n}\left(1, x_{2}-1\right) & p_{1}\left(\delta_{n}\left(0, x_{2}\right)-\delta_{n}\left(0, x_{2}-1\right)\right) \\
& +\left(1-p_{1}-p_{2}\right)\left(\delta_{n}\left(1, x_{2}\right)-\delta_{n}\left(1, x_{2}-1\right)\right) \\
& +p_{2}\left[\delta_{n}\left(1, x_{2}-1\right)-\delta_{n}\left(1, x_{2}-2\right)\right.
\end{array}\right\}
$$

To complete the proof that (iv) holds in the acceptance case, we need to show that $\gamma_{n}\left(1, x_{2}\right) \leqslant b+h_{1}-K^{\prime}$. For this purpose, combining Lemma 1(iii) with the induction hypothesis results in $\delta_{n+1}\left(1, x_{2}\right) \leqslant \delta_{n}\left(1, \leqslant x_{2}\right) \leqslant-K^{\prime}$. From (9),

$$
\begin{aligned}
\delta_{n+1}\left(1, x_{2}\right) & =\gamma_{n}\left(1, x_{2}\right)-\min \left\{b+h_{1}, K^{\prime}+\gamma_{n}\left(1, x_{2}\right)\right\} \\
& =-\min \left\{b+h_{1}-\gamma_{n}\left(1, x_{2}\right), K^{\prime}\right\} .
\end{aligned}
$$

Using $\delta_{n+1}\left(1, x_{2}\right)=-\min \left\{b+h_{1}-\gamma_{n}\left(1, x_{2}\right), \quad K^{\prime}\right\} \leqslant \delta_{n}(1$, $\left.x_{2}\right) \leqslant-K^{\prime}$ and proof by contradiction, we obtain $\gamma_{n}\left(1, x_{2}\right) \leqslant$ $b+h_{1}-K^{\prime}$ as follows. Suppose to the contrary that $\gamma_{n}\left(1, x_{2}\right)>b+h_{1}-K^{\prime}$. Then $b+h_{1}-\gamma_{n}\left(1, x_{2}\right)<K^{\prime}$. So $\delta_{n+1}\left(1, x_{2}\right)=-\left(b+h_{1}-\gamma_{n}\left(1, x_{2}\right)\right)>-K^{\prime}$. However, this contradicts $\delta_{n+1}\left(1 . x_{2}\right) \leqslant-K^{\prime}$. This contradiction establishes $\gamma_{n}\left(1, x_{2}\right) b+h_{1}-K^{\prime}$. This completes the inductive argument for $x_{1}=1$ for the acceptance case and for statement (B) for $x_{1}=1$.

Proof of Statement (A) for $\boldsymbol{x}_{\mathbf{1}}=\mathbf{1}$ : To analyse the validity of statement (A) for $x_{1}=1$ in period $n$, the induction hypothesis is that $\gamma_{n-1}\left(1, x_{2}-1\right)$ and $\gamma_{n-1}\left(1, x_{2}\right)$ satisfy either inequality (iii) or (iv) in period $n-1$.

Rejection: $\gamma_{n-1}\left(1, x_{2}\right)>b+h_{1}-K^{\prime}$. The induction hypothesis provides that $\gamma_{n-1}\left(1, x_{2}-1\right)=\gamma_{n-1}\left(1, x_{2}\right)>b+h_{1}-K^{\prime}$ for all $x_{2} \leqslant 0$. This is used in the below equality, which is obtained from (9).

$$
\begin{aligned}
\delta_{n}(1, & \left.x_{2}\right)-\delta_{n}\left(1, x_{2}-1\right) \\
= & \gamma_{n-1}\left(1, x_{2}\right)-\gamma_{n-1}\left(1, x_{2}-1\right) \\
& -\underbrace{\min \left\{b+h_{1}, K^{\prime}+\gamma_{n-1}\left(1, x_{2}\right)\right\}}_{=b+h_{1}} \\
& +\underbrace{\min \left\{b+h_{1}, K^{\prime}+\gamma_{n-1}\left(1, x_{2}-1\right)\right\}}_{=b+h_{1}} \\
= & 0 .
\end{aligned}
$$

Since $\delta_{n}\left(1, x_{2}\right)=\delta_{n}\left(1, x_{2}-1\right)$, either (i) or (ii) is satisfied.

Acceptance: $\gamma_{n-1}\left(1, x_{2}\right) b+h_{1}-K^{\prime}$. The induction hypothesis provides that $\gamma_{n-1}\left(1, x_{2}-1\right) \leqslant \gamma_{n-1}\left(1, x_{2}\right) \leqslant b+h_{1}-K^{\prime}$ for all $x_{2} \in \mathcal{N}^{-}$. Following the induction hypothesis

$$
\begin{aligned}
\delta_{n}(1, & \left.x_{2}\right)-\delta_{n}\left(1, x_{2}-1\right) \\
= & \gamma_{n-1}\left(1, x_{2}\right)-\gamma_{n-1}\left(1, x_{2}-1\right) \\
& -\min \left\{b+h_{1}, K^{\prime}+\gamma_{n-1}\left(1, x_{2}\right)\right\} \\
& +\min \left\{b+h_{1}, K^{\prime}+\gamma_{n-1}\left(1, x_{2}-1\right)\right\} \\
= & 0 .
\end{aligned}
$$


As in the rejection case, $\delta_{n}\left(1, x_{2}\right)=\delta_{n}\left(1, x_{2}-1\right)$. Thus either (i) or (ii) is satisfied. This completes the inductive argument for statement (A) for $x_{1}=1$.

Until now, it is proved that either (i) or (ii) holds for statement (A) over the pairs $\left(n=1, x_{1} \geqslant 0\right)$ and $(n \in\{0, \ldots$, $N\}, x_{1}=1$ ). It is also proved that either (iii) or (iv) holds for statement (B) over the pairs $\left(n=0, x_{1} \geqslant 0\right)$ and $\left(n \in\{0, \ldots, N\}, x_{1}=1\right)$. The result is extended to a pair $\left(n, x_{1}\right)$ for $n \geqslant 1$ and $x_{1} \geqslant 2$. This is done inductively by moving from $\left(n \in\{0, \ldots, N\}, x_{1}=1\right)$ to $(n \in\{0, \ldots, N\}$, $\left.x_{1}=2\right)$ and then to $\left(n \in\{0, \ldots, N\}, x_{1}=3\right)$ and so on. For a fixed $x_{1}$, we also traverse the points in $\left(n \in\{0, \ldots, N\}, x_{1}\right)$ in order of increasing $n$.

Proof of Statement (B) for $\mathbf{x}_{1} \geqslant 2$ : To prove (iii) or (iv) for inventory level $x_{1}$ in period $n$, assume the following induction hypotheses, which stem from statement (A).

In period $n$ with $x_{1}$, one and only one of the following statements holds.

(i) $\quad \delta_{n}\left(x_{1}, x_{2}-2\right)=\delta_{n}\left(x_{1}, x_{2}-1\right)=\delta_{n}\left(x_{1}, x_{2}\right)>-K^{\prime}$ or

(ii) $\delta_{n}\left(x_{1}, x_{2}-2\right) \leqslant \delta_{n}\left(x_{1}, x_{2}-1\right) \leqslant \delta_{n}\left(x_{1}, x_{2}\right) \leqslant-K^{\prime}$.

In period $n$ with $x_{1}-1$, one and only one of the following statements holds.

(i) $\quad \delta_{n}\left(x_{1}-1, x_{2}-1\right)=\delta_{n}\left(x_{1}-1, x_{2}\right)>-K^{\prime}$ or

(ii) $\delta_{n}\left(x_{1}-1, x_{2}-1\right) \leqslant \delta_{n}\left(x_{1}-1, x_{2}\right) \leqslant-K^{\prime}$.

Now statement (B) is validated in period $n$ by using the above induction hypotheses for two cases: acceptance and rejection.

Rejection: $\delta_{n}\left(x_{1}, x_{2}\right)>-K^{\prime}$. The induction hypothesis states that (i) is satisfied for $\left(n, x_{1}\right)$. Combining $\delta_{n}\left(x_{1}, x_{2}\right)>-K^{\prime}$ with Lemma 1(i), $\delta_{n}\left(x_{1}-1, x_{2}\right) \geqslant \delta_{n}\left(x_{1}, x_{2}\right)>-K^{\prime}$. So for ( $\left.n, x_{1}-1\right)$, only (i) can be satisfied. By using the fact that for both $\left(n, x_{1}\right)$ and $\left(n, x_{1}-1\right)$, only (i) statements are satisfied, the difference equation of $\gamma_{n}$ can be written starting with (11).

$$
\begin{aligned}
& \gamma_{n}\left(x_{1}, x_{2}\right)-\gamma_{n}\left(x_{1}, x_{2}-1\right) \\
& =p_{1}\left(\delta_{n}\left(x_{1}-1, x_{2}\right)-\delta_{n}\left(x_{1}-1, x_{2}-1\right)\right) \\
& +\left(1-p_{1}-p_{2}\right)\left(\delta_{n}\left(x_{1}, x_{2}\right)-\delta_{n}\left(x_{1}, x_{2}-1\right)\right) \\
& +p_{2}\left[\delta_{n}\left(x_{1}, x_{2}-1\right)-\delta_{n}\left(x_{1}, x_{2}-2\right)\right. \\
& \quad+\min \{0, \underbrace{K^{\prime}+\delta_{n}\left(x_{1}-1, x_{2}\right)}_{>0}\}
\end{aligned}
$$

$$
\begin{aligned}
-\min \{0, \underbrace{K^{\prime}+\delta_{n}\left(x_{1}, x_{2}-1\right)}_{>0}\} \\
-\min \{0, \underbrace{K^{\prime}+\delta_{n}\left(x_{1}-1, x_{2}-1\right)}_{>0}\} \\
\left.+\min \{0, \underbrace{K^{\prime}+\delta_{n}\left(x_{1}, x_{2}-2\right)}_{>0}\}\right]
\end{aligned}
$$$$
=0
$$

Since $\gamma_{n}\left(x_{1}, x_{2}\right)=\gamma_{n}\left(x_{1}, x_{2}-1\right)$, either (iii) or (iv) of Lemma 2 is satisfied.

Acceptance: $\delta_{n}\left(x_{1}, x_{2}\right) \leqslant K^{\prime}$. The induction hypothesis states that (ii) holds for $\left(n, x_{1}\right)$. This hypothesis is used in the following difference equation for $\gamma_{n}$.

$$
\begin{aligned}
& \gamma_{n}\left(x_{1}, x_{2}\right)-\gamma_{n}\left(x_{1}, x_{2}-1\right) \\
& =p_{1}\left(\delta_{n}\left(x_{1}-1, x_{2}\right)-\delta_{n}\left(x_{1}-1, x_{2}-1\right)\right) \\
& +\left(1-p_{1}-p_{2}\right)\left(\delta_{n}\left(x_{1}, x_{2}\right)-\delta_{n}\left(x_{1}, x_{2}-1\right)\right) \\
& +p_{2}\left[\delta_{n}\left(x_{1}, x_{2}-1\right)-\delta_{n}\left(x_{1}, x_{2}-2\right)\right. \\
& +\min \left\{0, K^{\prime}+\delta_{n}\left(x_{1}-1, x_{2}\right)\right\} \\
& -\min \{0, \underbrace{K^{\prime}+\delta_{n}\left(x_{1}, x_{2}-1\right)}_{\leqslant 0}\} \\
& -\min \left\{0, K^{\prime}+\delta_{n}\left(x_{1}-1, x_{2}-1\right)\right\} \\
& \left.+\min \{0, \underbrace{K^{\prime}+\delta_{n}\left(x_{1}, x_{2}-2\right)}_{\leqslant 0}\}\right] \\
& =p_{1}\left(\delta_{n}\left(x_{1}-1, x_{2}\right)-\delta_{n}\left(x_{1}-1, x_{2}-1\right)\right) \\
& +\left(1-p_{1}-p_{2}\right)\left(\delta_{n}\left(x_{1}, x_{2}\right)-\delta_{n}\left(x_{1}, x_{2}-1\right)\right) \\
& +p_{2}\left[\min \left\{0, K^{\prime}+\delta_{n}\left(x_{1}-1, x_{2}\right)\right\}\right. \\
& \left.-\min \left\{0, K^{\prime}+\delta_{n}\left(x_{1}-1, x_{2}-1\right)\right\}\right] \\
& \geqslant p_{1} \underbrace{\left(\delta_{n}\left(x_{1}-1, x_{2}\right)-\delta_{n}\left(x_{1}-1, x_{2}-1\right)\right)}_{\geqslant 0} \\
& +\left(1-p_{1}-p_{2}\right) \underbrace{\left(\delta_{n}\left(x_{1}, x_{2}\right)-\delta_{n}\left(x_{1}, x_{2}-1\right)\right)}_{\geqslant 0} \\
& +p_{2} \min \{0, \underbrace{\delta_{n}\left(x_{1}-1, x_{2}\right)-\delta_{n}\left(x_{1}-1, x_{2}-1\right)}_{\geqslant 0}\} \geqslant 0 \text {. }
\end{aligned}
$$

The second equality above is obtained by the induction hypothesis that $\delta_{n}\left(x_{1}, x_{2}\right) \leqslant-K^{\prime}$. Then Proposition 1 is used to get the first inequality. For $\left(n, x_{1}-1\right)$, whether (i) or (ii) is satisfied, it follows that $\delta_{n}\left(x_{1}-1, x_{2}\right)-\delta_{n}\left(x_{1}-1\right.$, 
$\left.x_{2}-1\right) \geqslant 0$. The result follows from this fact and the induction hypothesis.

To complete the proof that Lemma 2(iv) holds for the acceptance case, it is shown that $\gamma_{n}\left(x_{1}, x_{2}\right) \leqslant b+h_{1}-K^{\prime}$. For $x_{2}-1$, using (8) and Proposition 1,

$$
\begin{aligned}
\delta_{n+1} & \left(x_{1}, x_{2}\right) \\
\geqslant & \gamma_{n}\left(x_{1}, x_{2}\right)-b-h_{1} \\
& +\min \left\{0, \gamma_{n}\left(x_{1}-1, x_{2}+1\right)-\gamma_{n-1}\left(x_{1}, x_{2}\right)\right\} \\
= & \gamma_{n}\left(x_{1}, x_{2}\right)-b-h_{1} \\
& +\min \{0, \underbrace{\gamma_{n}\left(x_{1}-1, x_{2}+1\right)-\gamma_{n}\left(x_{1}, x_{2}+1\right)}_{\geqslant 0} \\
& +\underbrace{\gamma_{n}\left(x_{1}, x_{2}+1\right)-\gamma_{n-1}\left(x_{1}, x_{2}\right)}\} \\
= & \gamma_{n}\left(x_{1}, x_{2}\right)-b-h_{1} .
\end{aligned}
$$

$\gamma_{n}\left(x_{1}-1, x_{2}+1\right)-\gamma_{n}\left(x_{1}, x_{2}+1\right) \geqslant 0$ is by Lemma 1(ii). $\gamma_{n}\left(x_{1}, x_{2}+1\right)-\gamma_{n-1}\left(x_{1}, x_{2}\right)$ follows from the induction hypothesis.

On the other hand, combining Lemma 1(iii) with the acceptance condition $\delta_{n}\left(x_{1}, x_{2}\right) \leqslant-K^{\prime}, \delta_{n+1}\left(x_{1}, x_{2}\right) \leqslant \delta_{n}\left(x_{1}\right.$, $\left.x_{2}\right) \leqslant-K^{\prime}$ or simply $\delta_{n+1}\left(x_{1}, x_{2}\right) \leqslant-K^{\prime}$. Combining this result with $\delta_{n+1}\left(x_{1}, x_{2}\right) \geqslant \gamma_{n}\left(x_{1}, x_{2}\right)-b-h_{1}$, we get $\gamma_{n}\left(x_{1}\right.$, $\left.x_{2}\right) \leqslant b+h_{1}-K^{\prime}$, which is (iv) of Lemma 2 .

For $x_{2}=0, \quad$ using (9), $\delta_{n+1}\left(x_{1}, x_{2}\right)=\gamma_{n}\left(x_{1}, x_{2}\right)-$ $\min \left\{b+h_{1}, K^{\prime}+\gamma_{n-1}\left(x_{1}, x_{2}\right)\right\} \geqslant \gamma_{n}\left(x_{1}, x_{2}\right)-b-h_{1} \quad$. Again, by combining this result with the acceptance condition, it follows that $\gamma_{n}\left(x_{1}, x_{2}\right)<b+h_{1}-K^{\prime}$. This completes the proof that for $x_{1} \geqslant 2, \gamma_{n}\left(x_{1}, x_{2}-1\right) \leqslant \gamma_{n}\left(x_{1}\right.$, $\left.x_{2}\right) \leqslant b+h_{1}-K^{\prime}$, which is (iv) of Lemma 2 .

Proof of Statement (A) for $\boldsymbol{x}_{\mathbf{1}} \geqslant \mathbf{2}$ : To prove statement (A) of Lemma 2 for period $n$ and inventory level $x_{1}$, assume the following induction hypotheses for $x_{2} \leqslant-1$, which stem from statement (B).

In period $n-1$ with $x_{1}$, one and only one of the following statements holds.

$$
\text { (iii) } \begin{aligned}
\gamma_{n-1}\left(x_{1}, x_{2}-1\right) & =\gamma_{n-1}\left(x_{1}, x_{2}\right) \\
& =\gamma_{n-1}\left(x_{1}, x_{2}+1\right) \\
& >b+h_{1}-K^{\prime} \text { or } \\
\text { (iv) } \quad \gamma_{n-1}\left(x_{1}, x_{2}-1\right) & \leqslant \gamma_{n-1}\left(x_{1}, x_{2}\right) \\
& \leqslant \gamma_{n-1}\left(x_{1}, x_{2}+1\right) \\
& \leqslant b+h_{1}-K^{\prime} .
\end{aligned}
$$

In period $n-1$ with $x_{1}-1$, one and only one of the following statements holds.

$$
\text { (iii) } \begin{aligned}
\gamma_{n-1}\left(x_{1}-1, x_{2}\right) & =\gamma_{n-1}\left(x_{1}-1, x_{2}+1\right) \\
& >b+h_{1}-K^{\prime} \text { or }
\end{aligned}
$$

$$
\text { (iv) } \begin{aligned}
\gamma_{n-1}\left(x_{1}-1, x_{2}\right) & \leqslant \gamma_{n-1}\left(x_{1}-1, x_{2}+1\right) \\
& \leqslant b+h_{1}-K^{\prime} .
\end{aligned}
$$

To prove statement (A), induction hypotheses are made over the range of $x_{2} \leqslant-1$ instead of $x_{2} \leqslant 0$. This is because $x_{2}+1$ is used in the induction hypotheses (iii) and (iv) above. The proof for $x_{2}=0$ is done after the proof is completed for $x_{2} \leqslant-1$.

The proof is done for rejection and acceptance cases separately.

Rejection: $\gamma_{n-1}\left(x_{1}, x_{2}+1\right)>b+h_{1}-K^{\prime}$. The induction hypothesis says that (iii) holds for $\left(n-1, x_{1}\right)$. Combining this fact with Lemma 1(i), it follows that (iii) holds for $\left(n-1, x_{1}-1\right)$. Then by using (8) for $x_{2} \leqslant-1$,

$$
\begin{aligned}
& \delta_{n}\left(x_{1}, x_{2}\right)- \delta_{n}\left(x_{1}, x_{2}-1\right) \\
&= \gamma_{n-1}\left(x_{1}, x_{2}\right)-\gamma_{n-1}\left(x_{1}, x_{2}-1\right) \\
&+\min \{b+h_{1}, \underbrace{K^{\prime}+\gamma_{n-1}\left(x_{1}-1, x_{2}+1\right)}_{>b+h_{1}}\} \\
&-\min \{b+h_{1}, \underbrace{K^{\prime}+\gamma_{n-1}\left(x_{1}, x_{2}\right)}_{>b+h_{1}}\} \\
&-\min \{b+h_{1}, \underbrace{K^{\prime}+\gamma_{n-1}\left(x_{1}-1, x_{2}\right)}_{>b+h_{1}}\} \\
&+\min \{b+h_{1}, \underbrace{K^{\prime}+\gamma_{n-1}\left(x_{1}, x_{2}-1\right)}_{>b+h_{1}}\}=0 .
\end{aligned}
$$

Since $\delta_{n}\left(x_{1}, x_{2}\right)=\delta_{n}\left(x_{1}, x_{2}-1\right)$, either (i) or (ii) of Lemma 2 is satisfied.

Acceptance: $\gamma_{n-1}\left(x_{1}, x_{2}+1\right) b+h_{1}-K^{\prime}$. The induction hypothesis says that (iv) holds for $\left(n-1, x_{1}\right)$. This fact is used to obtain the below difference equation.

$$
\begin{aligned}
\delta_{n}\left(x_{1}, x_{2}\right)- & \delta_{n}\left(x_{1}, x_{2}-1\right) \\
= & \gamma_{n-1}\left(x_{1}, x_{2}\right)-\gamma_{n-1}\left(x_{1}, x_{2}-1\right) \\
& +\min \left\{b+h_{1}, K^{\prime}+\gamma_{n-1}\left(x_{1}-1, x_{2}+1\right)\right\} \\
& -\min \{b+h_{1}, \underbrace{K^{\prime}+\gamma_{n-1}\left(x_{1}, x_{2}\right)}_{\leqslant b+h_{1}}\} \\
& -\min \left\{b+h_{1}, K^{\prime}+\gamma_{n-1}\left(x_{1}-1, x_{2}\right)\right\} \\
& +\min \{b+h_{1}, \underbrace{K^{\prime}+\gamma_{n-1}\left(x_{1}, x_{2}-1\right)}_{\leqslant b+h_{1}}\} \\
= & \min \left\{b+h_{1}, K^{\prime}+\gamma_{n-1}\left(x_{1}-1, x_{2}+1\right)\right\} \\
& -\min \left\{b+h_{1}, K^{\prime}+\gamma_{n-1}\left(x_{1}-1, x_{2}\right)\right\} .
\end{aligned}
$$

For $\left(n-1, x_{1}-1\right)$, either induction hypothesis (iii) or (iv) holds. If (iii) holds, $\delta_{n}\left(x_{1}, x_{2}\right)-\delta_{n}\left(x_{1}, x_{2}-1\right)=0$. So either (i) 
or (ii) of Lemma 2 is satisfied. If (iv) holds, $\delta_{n}\left(x_{1}\right.$, $\left.x_{2}\right)-\delta_{n}\left(x_{1}, x_{2}-1\right)=\gamma_{n-1}\left(x_{1}-1, x_{2}+1\right)-\gamma_{n-1}\left(x_{1}-1, x_{2}\right) \geqslant 0$.

To complete the proof for the acceptance case, it should be shown that when the induction hypothesis (iv) holds for $\left(n-1, x_{1}-1\right)$, then $\delta_{n}\left(x_{1}, x_{2}\right) \leqslant-K^{\prime}$ for $x_{2} \leqslant-1$. From (8), $\delta_{n}\left(x_{1}, x_{2}\right)$ is as follows.

$$
\begin{aligned}
& \delta_{n}\left(x_{1}, x_{2}\right) \\
& =\gamma_{n-1}\left(x_{1}, x_{2}\right)-b-h_{1} \\
& \quad+\min \{b+h_{1}, \underbrace{K^{\prime}+\gamma_{n-1}\left(x_{1}-1, x_{2}+1\right)}_{\leqslant b+h_{1}}\} \\
& \quad-\min \{b+h_{1}, \underbrace{K^{\prime}+\gamma_{n-1}\left(x_{1}, x_{2}\right)}_{\leqslant b+h_{1}}\} \\
& =\gamma_{n-1}\left(x_{1}-1, x_{2}+1\right)-b-h_{1} \leqslant-K^{\prime} .
\end{aligned}
$$

The two inequalities used above follow from the induction hypotheses. This completes the proof of statement $(\mathrm{A})$ for $x_{1} \geqslant 2$ and $x_{2} \leqslant-1$.

To prove statement (A) for $x_{1} \geqslant 2$ and $x_{2}=0$, first consider an induction hypothesis that is a rejection case $\gamma_{n-1}\left(x_{1}, x_{2}\right)>b+h_{1}-K^{\prime}$. By statement (B) and Lemma 1(ii), it follows that $\gamma_{n-1}\left(x_{1}-1, x_{2}\right) \geqslant \gamma_{n-1}\left(x_{1}\right.$, $\left.x_{2}-1\right)=\gamma_{n-1}\left(x_{1}, x_{2}\right)>b+h_{1}-K^{\prime}$. By using these facts in (8) and (9), we get

$$
\begin{aligned}
& \delta_{n}\left(x_{1}, x_{2}\right)-\delta_{n}\left(x_{1}, x_{2}-1\right) \\
&= \gamma_{n-1}\left(x_{1}, x_{2}\right)-\gamma_{n-1}\left(x_{1}, x_{2}-1\right)+b+h_{1} \\
&-\min \left\{b+h_{1}, K^{\prime}+\gamma_{n-1}\left(x_{1}, x_{2}\right)\right\} \\
&+\min \left\{b+h_{1}, K^{\prime}+\gamma_{n-1}\left(x_{1}, x_{2}-1\right)\right\} \\
& \quad-\min \left\{b+h_{1}, K^{\prime}+\gamma_{n-1}\left(x_{1}-1, x_{2}\right)\right\}=0 .
\end{aligned}
$$

Thus either (i) or (ii) of Lemma 2 is satisfied.

For $x_{1} \geqslant 2$ and $x_{2}=0$, the induction hypothesis for an acceptance case is that $\gamma_{n-1}\left(x_{1}, x_{2}\right) \leqslant b+h_{1}-K^{\prime}$. By statement (B), $\gamma_{n-1}\left(x_{1}, x_{2}-1\right) \gamma_{n-1}\left(x_{1}, x_{2}\right) \leqslant b+h_{1}-K^{\prime}$. Using this fact with (8) and (9) yields

$$
\begin{aligned}
& \delta_{n}\left(x_{1}, x_{2}\right)-\delta_{n}\left(x_{1}, x_{2}-1\right) \\
&=\gamma_{n-1}\left(x_{1}, x_{2}\right)-\gamma_{n-1}\left(x_{1}, x_{2}-1\right)+b+h_{1} \\
& \quad-\min \left\{b+h_{1}, K^{\prime}+\gamma_{n-1}\left(x_{1}, x_{2}\right)\right\} \\
& \quad+\min \left\{b+h_{1}, K^{\prime}+\gamma_{n-1}\left(x_{1}, x_{2}-1\right)\right\} \\
& \quad-\min \left\{b+h_{1}, K^{\prime}+\gamma_{n-1}\left(x_{1}-1, x_{2}\right)\right\} \\
&= b+h_{1}-\min \left\{b+h_{1}, K^{\prime}+\gamma_{n-1}\left(x_{1}-1, x_{2}\right)\right\} \geqslant 0 .
\end{aligned}
$$

To complete the proof for the acceptance case for $x_{2}=0$, it should be shown that when the induction hypothesis $\gamma_{n-1}\left(x_{1}, x_{2}\right) b+h_{1}-K^{\prime}$ holds, then $\delta_{n}\left(x_{1}, x_{2}\right) \leqslant-K^{\prime} . \quad$ By using (9),

$$
\delta_{n}\left(x_{1}, x_{2}\right)=\gamma_{n-1}\left(x_{1}, x_{2}\right)-\min \{b+h_{1}, \underbrace{K^{\prime}+\gamma_{n-1}\left(x_{1}, x_{2}\right)}_{\leqslant b+h_{1}}\}
$$$$
=-K^{\prime}
$$

The result directly follows from the induction hypothesis. This completes the proof of Lemma 2.

Proof of Lemma 3 Consider the following statements.

(i) $\delta_{n}\left(x_{1}, x_{2}\right)>-K^{\prime}$, if $\gamma_{n-1}\left(x_{1}, x_{2}+1\right)>b+h_{1}+K^{\prime}$

(ii) $\delta_{n}\left(x_{1}, x_{2}\right) \leqslant-K^{\prime}$, if $\gamma_{n-1}\left(x_{1}, x_{2}+1\right) \leqslant b+h_{1}-K^{\prime}$.

Note that the contrapositive of (i) is $\gamma_{n-1}\left(x_{1}\right.$, $\left.x_{2}+1\right) b+h_{1}-K^{\prime}$ if $\delta_{n}\left(x_{1}, x_{2}\right) \leqslant-K^{\prime}$. Since this contrapositive combined with (ii) is equivalent to Lemma 3 , it suffices to prove (i) and (ii). The proof is separated into two cases: $\left[x_{1} \geqslant 1, x_{2}=0\right.$ or $\left.x_{1}=1, x_{2} \leqslant-1\right]$ and $\left[x_{1} \geqslant 2, x_{2} \leqslant-1\right]$.

Case 1: $\left[x_{1} \geqslant 1, x_{2}=0\right.$ or $\left.x_{1}=1, x_{2} \leqslant-1\right]$ Consider $x_{1} \geqslant 1$ and $x_{2}=0$, (9) can then be rewritten as $\delta_{n} \times$ $\left(x_{1}, 0\right)=\gamma_{n-1}\left(x_{1}, 0\right)-\min \left\{b+h_{1}, K^{\prime}+\gamma_{n-1} \times\right.$ $\left.\left(x_{1}, 0\right)\right\}$, which leads to

$$
\begin{aligned}
& b+h_{1}+\delta_{n}\left(x_{1}, 0\right) \\
& \quad=\max \left\{\gamma_{n-1}\left(x_{1}, 0\right), b+h_{1}-K^{\prime}\right\} .
\end{aligned}
$$

When $\delta_{n}\left(x_{1}, 0\right)>-K^{\prime}$, the last equality gives $b+h_{1}-K^{\prime}<$ $\max \left\{\gamma_{n-1}\left(x_{1}, 0\right), \quad b+h_{1}-K^{\prime}\right\}, \quad$ which in turn implies $\gamma_{n-1}\left(x_{1}, 0\right)>b+h_{1}-K^{\prime}$. When $\delta_{n}\left(x_{1}, 0\right) \leqslant-K^{\prime}$, we similarly obtain $b+h_{1}-K^{\prime} \geqslant \max \left\{\gamma_{n-1}\left(x_{1}, 0\right), b+h_{1}-K^{\prime}\right\}$, which leads to $\gamma_{n-1}\left(x_{1}, 0\right) \leqslant b+h_{1}-K^{\prime}$. The last two statements prove (i) and (ii).

Consider $x_{1}=1$ and $x_{2} \leqslant-10$, (9) can be rewritten as

$$
\delta_{n}\left(1, x_{2}\right)=-\min \left\{b+h_{1}-\gamma_{n-1}\left(1, x_{2}\right), K^{\prime}\right\} .
$$

Proof of (i): If $\gamma_{n-1}\left(1, x_{2}+1\right)>b+h_{1}-K^{\prime}$, then $\gamma_{n-1}(1$, $\left.x_{2}\right)=\gamma_{n-1}\left(1, x_{2}+1\right)>b+h_{1}-K^{\prime}$ by Lemma 2. Using $b+h_{1}-\gamma_{n-1}\left(1, x_{2}\right)<$ in (A.13), we obtain that $\delta_{n}(1$, $\left.x_{2}\right)=-\left(b+h_{1}-\gamma_{n-1}\left(1, x_{2}\right)\right)>-K^{\prime}$.

Proof of (ii): If $\gamma_{n-1}\left(1, x_{2}+1\right) \leqslant b+h_{1}-K^{\prime}$, then $\gamma_{n-1}(1$, $\left.x_{2}\right) \gamma_{n-1}\left(1, x_{2}+1\right) \leqslant b+h_{1}-K^{\prime}$ from Lemma 2. Equation (A.13) becomes $\delta_{n}\left(1, x_{2}\right)=-K^{\prime}$, which proves (ii).

Case 2: $\left[x_{1} \geqslant 2, x_{2} \leqslant-1\right]$. In this case,

$$
\begin{aligned}
& \delta_{n}\left(x_{1}, x_{2}\right) \\
&= \gamma_{n-1}\left(x_{1}, x_{2}\right)-b-h_{1} \\
&+\min \left\{b+h_{1}, K^{\prime}+\gamma_{n-1}\left(x_{1}-1, x_{2}+1\right)\right\} \\
&-\min \left\{b+h_{1}, K^{\prime}+\gamma_{n-1}\left(x_{1}, x_{2}\right)\right\} . \square \quad(\text { A. }
\end{aligned}
$$


Table A1 Complete cost computations for the illustrative example

\begin{tabular}{|c|c|c|c|c|c|c|c|c|c|c|c|c|c|c|}
\hline \multicolumn{5}{|c|}{$n=0$} & \multicolumn{5}{|c|}{$n=1$} & \multicolumn{5}{|c|}{$n=2$} \\
\hline$x_{1}$ & $x_{2}$ & $x_{b}$ & $V_{n}^{\mathrm{C}}$ & $Y_{n}^{\mathrm{C}}$ & $x_{1}$ & $x_{2}$ & $x_{b}$ & $V_{n}^{\mathrm{C}}$ & $Y_{n}^{\mathrm{C}}$ & $x_{1}$ & $x_{2}$ & $x_{b}$ & $V_{n}^{\mathrm{C}}$ & $Y_{n}^{\mathrm{C}}$ \\
\hline 0 & 0 & 0 & 0 & - & 0 & 0 & 0 & 3.2 & 0 & 0 & 0 & 0 & 9.6 & 3.2 \\
\hline 0 & 0 & 1 & 0 & - & 0 & 0 & 1 & 7.2 & 4 & 0 & 0 & 1 & - & 11.2 \\
\hline 0 & 0 & 2 & 0 & - & 0 & 0 & 2 & - & 8 & 0 & 1 & 0 & 5.35 & 2.7 \\
\hline 0 & 1 & 0 & 3 & - & 0 & 1 & 0 & 2.7 & 3 & 0 & 1 & 1 & - & 10.7 \\
\hline 0 & 1 & 1 & 3 & - & 0 & 1 & 1 & 6.7 & 7 & 0 & 2 & 0 & 6 & 5.7 \\
\hline 0 & 1 & 2 & 3 & - & 0 & 1 & 2 & - & 11 & 0 & 2 & 1 & - & 11.7 \\
\hline 0 & 2 & 0 & 6 & - & 0 & 2 & 0 & 5.7 & 6 & 1 & 0 & 0 & 7.83 & 4.1 \\
\hline 0 & 2 & 1 & 6 & - & 0 & 2 & 1 & 9.7 & 10 & 1 & 0 & 1 & - & 12.1 \\
\hline 0 & 2 & 2 & 6 & 一 & 0 & 2 & 2 & 一 & 14 & 1 & 1 & 0 & 3.58 & 3.6 \\
\hline 1 & 0 & 0 & 3 & - & 1 & 0 & 0 & 4.1 & 3 & 1 & 1 & 1 & - & 11.6 \\
\hline 1 & 0 & 1 & 3 & - & 1 & 0 & 1 & 8.1 & 7 & 1 & 2 & 0 & 4.83 & 6.6 \\
\hline 1 & 0 & 2 & 3 & - & 1 & 0 & 2 & - & 11 & 1 & 2 & 1 & - & 12.6 \\
\hline 1 & 1 & 0 & 6 & - & 1 & 1 & 0 & 3.6 & 6 & 2 & 0 & 0 & 9.2 & 7.1 \\
\hline 1 & 1 & 1 & 6 & - & 1 & 1 & 1 & 7.6 & 10 & 2 & 0 & 1 & - & 13.1 \\
\hline 1 & 1 & 2 & 6 & - & 1 & 1 & 2 & - & 14 & 2 & 1 & 0 & 5.95 & 6.6 \\
\hline 1 & 2 & 0 & 9 & - & 1 & 2 & 0 & 6.6 & 9 & 2 & 1 & 1 & - & 12.6 \\
\hline 1 & 2 & 1 & 9 & - & 1 & 2 & 1 & 10.6 & 13 & 2 & 2 & 0 & 7.2 & 9.6 \\
\hline 1 & 2 & 2 & 9 & 一 & 1 & 2 & 2 & - & 17 & 2 & 2 & 1 & - & 15.6 \\
\hline 2 & 0 & 0 & 6 & - & 2 & 0 & 0 & 7.1 & 6 & & & & & \\
\hline 2 & 0 & 1 & 6 & - & 2 & 0 & 1 & 11.1 & 10 & & & & & \\
\hline 2 & 0 & 2 & 6 & - & 2 & 0 & 2 & - & 14 & & & & & \\
\hline 2 & 1 & 0 & 9 & - & 2 & 1 & 0 & 6.6 & 9 & & & & & \\
\hline 2 & 1 & 1 & 9 & - & 2 & 1 & 1 & 10.6 & 13 & & & & & \\
\hline 2 & 1 & 2 & 9 & - & 2 & 1 & 2 & - & 17 & & & & & \\
\hline 2 & 2 & 0 & 12 & - & 2 & 2 & 0 & 9.6 & 12 & & & & & \\
\hline 2 & 2 & 1 & 12 & - & 2 & 2 & 1 & 13.6 & 16 & & & & & \\
\hline 2 & 2 & 2 & 12 & - & 2 & 2 & 2 & - & 20 & & & & & \\
\hline
\end{tabular}

Proof of (i) If $\gamma_{n-1}\left(x_{1}, x_{2}+1\right)>b+h_{1}-K^{\prime}$, then $\gamma_{n-1}\left(x_{1}\right.$, $\left.x_{2}\right)=\gamma_{n-1}\left(x_{1}, x_{2}+1\right)>b+h_{1}-K^{\prime}$ from Lemma 2 . Also, $\gamma_{n-1}\left(x_{1}-1, x_{2}\right) \geqslant \gamma_{n-1}\left(x_{1}, x_{2}\right)$ by Lemma 1 . Then from (A.14),

$$
\begin{aligned}
\delta_{n}\left(x_{1}, x_{2}\right) & \\
= & \gamma_{n-1}\left(x_{1}, x_{2}\right)-b-h_{1} \\
& +\min \{b+h_{1}, \underbrace{K^{\prime}+\gamma_{n-1}\left(x_{1}-1, x_{2}+1\right)}_{>b+h_{1}}\} \\
& -\min \{b+h_{1}, \underbrace{K^{\prime}+\gamma_{n-1}\left(x_{1}, x_{2}\right)}_{>b+h_{1}}\}>-K^{\prime} .
\end{aligned}
$$

Proof of (ii) If $\gamma_{n-1}\left(x_{1}, x_{2}+1\right) b+h_{1}-K^{\prime}$, then $\gamma_{n-1}\left(x_{1}\right.$, $\left.x_{2}\right) \leqslant \gamma_{n-1}\left(x_{1}, x_{2}+1\right) b+h_{1}-K^{\prime}$ by Lemma 2 . Using $K^{\prime}+\gamma_{n-1}\left(x_{1}, x_{2}\right) \leqslant b+h_{1}$ in (37),

$$
\begin{aligned}
\delta_{n}( & \left.x_{1}, x_{2}\right) \\
= & -b-h_{1}-K^{\prime} \\
& +\underbrace{\min \left\{b+h_{1}, K^{\prime}+\gamma_{n-1}\left(x_{1}-1, x_{2}+1\right)\right\}}_{\leqslant b+h_{1}} \\
\leqslant & -K^{\prime} . \quad \square
\end{aligned}
$$

Proof of Lemma 4: This proof is very similar to the proof of Lemma 1(i)-1(ii). The only difference is in the initialization step of the inductive argument. This time, we initialize with $\gamma_{0}\left(x_{1}, x_{2}\right)=-h_{1} \rrbracket_{x_{1} \geqslant 1}$, which is nonincreasing in $x_{1}$. From this point on, the proof of Lemma 1(i)-1(ii) can be replicated under $h_{1}=0$ to make induction arguments (Table A1).

Received September 2011; accepted September 2012 after one revision 